DIW BERLIN

Discussion

Papers

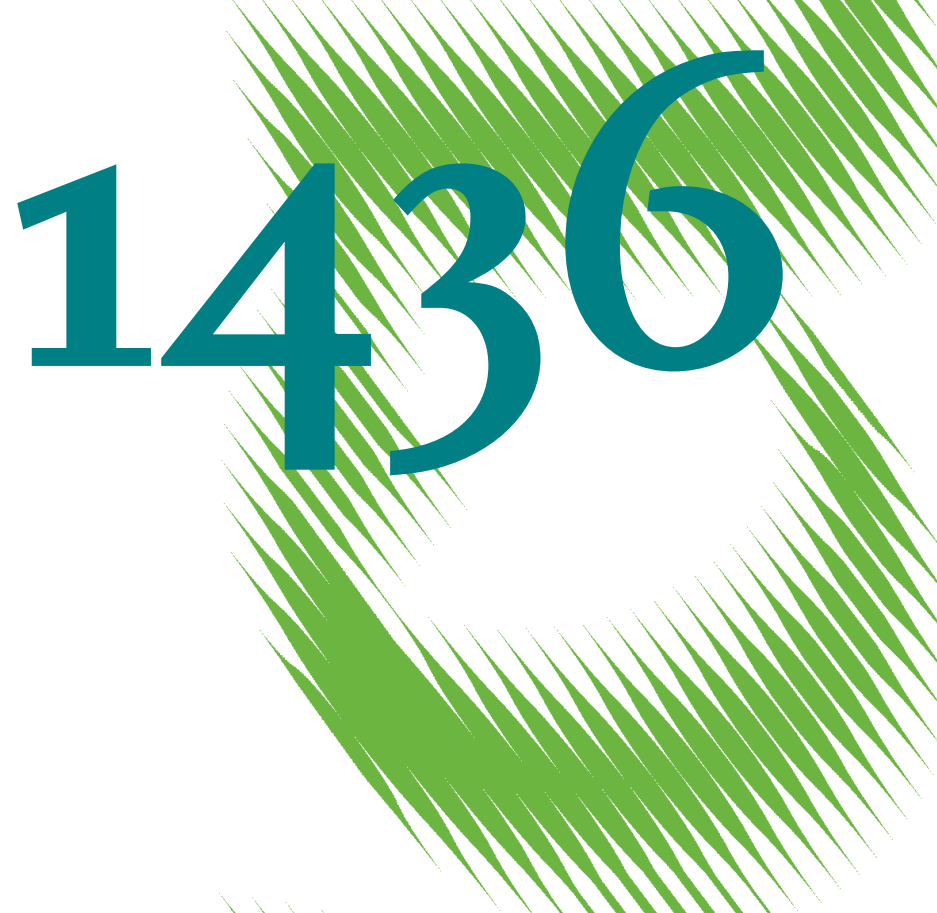

Sovereign Risk, Interbank Freezes, and Aggregate Fluctuations 
Opinions expressed in this paper are those of the author(s) and do not necessarily reflect views of the institute.

IMPRESSUM

(C) DIW Berlin, 2014

DIW Berlin

German Institute for Economic Research

Mohrenstr. 58

10117 Berlin

Tel. +49 (30) $89789-0$

Fax +49 (30) $89789-200$

http://www.diw.de

ISSN electronic edition 1619-4535

Papers can be downloaded free of charge from the DIW Berlin website:

http://www.diw.de/discussionpapers

Discussion Papers of DIW Berlin are indexed in RePEc and SSRN:

http://ideas.repec.org/s/diw/diwwpp.html

http://www.ssrn.com/link/DIW-Berlin-German-Inst-Econ-Res.html 


\title{
Sovereign risk, interbank freezes, and aggregate fluctuations*
}

\author{
Philipp Engler ${ }^{\ddagger 2}$ and Christoph Große Steffen ${ }^{\S 1,2}$ \\ ${ }^{1}$ German Institute for Economic Research (DIW Berlin) \\ ${ }^{2}$ Freie Universität Berlin
}

\begin{abstract}
This paper studies the bank-sovereign link in a dynamic stochastic general equilibrium set-up with strategic default on public debt. Heterogeneous banks give rise to an interbank market where government bonds are used as collateral. A default penalty arises from a breakdown of interbank intermediation that induces a credit crunch. Government borrowing under limited commitment is costly ex ante as bank funding conditions tighten when the quality of collateral drops. This lowers the penalty from an interbank freeze and feeds back into default risk. The arising amplification mechanism propagates aggregate shocks to the macroeconomy. The model is calibrated using Spanish data and is capable of reproducing key business cycle statistics alongside stylized facts during the European sovereign debt crisis.
\end{abstract}

Key words: Sovereign default; Interbank market; Bank-sovereign link; NonRicardian effects; Secondary markets; Domestic debt; Occasionally binding constraint

JEL Codes: E43; E44; F34; H63

\footnotetext{
*We wish to thank Niccolò Battistini, Dennis Bonam, Fernando Broner, Aitor Erce, Juan Carlos Hatchondo, Simon Junker, Stephan Luck, Alberto Martin, Guido Sandleris, Christoph Trebesch and Vivian Yue for valuable discussions and suggestions. We also would like to thank participants at UCLA, DIW GC Workshop 2012, Conference on the Global Financial Crisis Southampton 2013, Spring Meeting of Young Economist 2013, 2013 ZEW Conference on Recent Developments in Macro, 2013 European Economic Association Meeting, 2013 VfS Annual Congress, 2014 Berlin Macro Network Workshop, 2014 Barcelona GSE Summer Forum, 2014 North American Summer Meeting of the Econometric Society, 2014 Conference on Computing in Economics and Finance, and Bundesbank joint Workshop on Fiscal Policy and Macroeconomic Performance for comments.

${ }^{\ddagger}$ Freie Universität Berlin, Boltzmannstraße 20, Room 254, 14195 Berlin, Germany. E-mail: philipp.engler(at)fu-berlin.de

$\S$ Corresponding author. German Institute for Economic Research (DIW Berlin), Mohrenstraße 58, 10117 Berlin, Germany. E-mail: cgrossesteffen(at)diw.de; tel.: +49 30897 89-596.
} 


\section{Introduction}

The European sovereign debt crisis has highlighted the pivotal role of public debt held by the domestic financial sector in creating a bank-sovereign link that amplifies adverse shocks in the presence of fiscal stress. The close interdependence between sovereign risk, financial stability and economic activity exposed the fragility of public debt positions in advanced economies. In particular, we make three observations during the crisis: (i) Banks in countries with an elevated risk premium on government debt underwent difficulties in tapping wholesale funding markets. (ii) The interest rates of the public and the private sector started to be highly correlated in countries under fiscal stress. (iii) Countries in the euro area periphery in very deep recessions experienced particularly strong increases in their yield spreads.

Until recently, the existing literature on strategic sovereign default has focused on emerging market debt. ${ }^{1}$ In this paper, we attempt to close the gap in the quantitativetheoretic literature by proposing a model of optimal sovereign default for advanced economies. We use the model to answer the following question: What makes debt positions in advanced and financially developed economies vulnerable? We find that the adverse feedback loop in Europe can be rationalised by the concept of strategic default and that ex ante spillovers from sovereign risk to financial market allocations are an important source of sovereign risk.

This paper makes three contributions. First, we nest a bank-sovereign link in a quantitative dynamic stochastic general equilibrium setting that gives rise to an endogenous penalty from defaulting. ${ }^{2}$ Based on the classic work of Eaton \& Gersovitz (1981), a model of strategic sovereign default in a small open economy is augmented with a heterogeneous banking sector. Banks allocate financial resources on a secured interbank market where government bonds serve as collateral. The economic cost of default is due to an ensuing credit crunch in response to an interbank market freeze as collateral looses its market value. ${ }^{3}$ In line with previous findings, the penalty works as a powerful enforcement mechanism which is able to support higher debt levels compared to related quantitative frameworks. ${ }^{4}$ Thereby, the model is able to rationalise higher debt levels and lower frequencies of default that are typically observed in financially developed, advanced economies. While the described mechanism is not limited to advanced economies, we find, similar to Gennaioli et al. (2014), that the penalty is higher for financially more developed economies.

Second, we formalise an amplification mechanism that arises from endogenously evolving sovereign risk. A deterioration of the quality of underlying collateral assets gives rise to a risk premium that pushes up bank funding costs and dampens financial intermediation (Barro 1976). Sovereign risk propagates into higher costs of external finance for the non-financial sector, in turn curbing private credit demand and de-

\footnotetext{
${ }^{1}$ Arellano (2008) and Aguiar \& Gopinath (2006) are seminal studies in this field.

${ }^{2}$ There is a long academic debate on the enforcement problem of government debt. In recent work, endogenous penalties have gained more attention compared to reputational arguments as presented in Bulow \& Rogoff (1989), Cole \& Kehoe (1998), and Grossman \& van Huyck (1988), among others.

${ }^{3}$ Empirical findings of Dell'ariccia et al. (2005) document a domestic credit crunch in response to a banking crisis which lowers aggregate production.

${ }^{4}$ See Dooley (2000) and Kumhof \& Tanner (2008).
} 
pressing aggregate output. As a result, the penalty from the collapse of the interbank market turns less painful in relative terms during times of fiscal stress, feeding back into an increase of sovereign risk. ${ }^{5}$

Third, we calibrate the model using Spanish data. The quantitative simulation exercise shows that the model is capable of reproducing key business cycle statistics alongside the stylised facts from above. Although the quantitative predictions of the model are broadly in line with the results from the literature on sovereign default in emerging markets, there are three differences in comparison to the Argentinian default of 2001 that has often served as an example of an emerging market sovereign default. Calibrated to an advanced and financially developed economy, we find that (i) recessions preceding a default event are more severe in advanced economies; (ii) there is a stronger impact effect of default on output; (iii) recessions last longer after a default. Thus, the model is supporting the view of long-lasting financial recessions (Cerra \& Saxena 2008) as opposed to a strong recovery observed in the follow-up to emerging market debt crises (Calvo et al. 2006). High persistence and slow recovery are related to banks' need to accumulate collateral from retained earnings during the post-default period.

The paper mainly contributes to three branches of the existing literature. First, we follow Mendoza \& Yue (2012) in breaking the disconnect between sovereign default risk and the business cycle in a quantitative setting. The trade-off inherent to the default decision in their model is linked to the trade sector that depends on access to foreign finance. We extend their analysis by structurally modelling a banking sector that determines domestic borrowing conditions of the private sector. The model's propagation mechanism leads to a co-movement of private and public sector interest rates during a debt crisis. This result sheds new insights on the countercyclical nature of interest rates, as previously analysed by Neumeyer \& Perri (2005) and Uribe \& Yue (2006). Fernández \& Gulan (2012) explain counter-cyclical private sector interest rates by financial frictions on the side of entrepreneurs. We separate from their work by providing a different explanation through the interaction of the enforcement problem on the government side with frictions in the banking sector.

Second, our interpretation of the bank-sovereign link is motivated by the role of government debt in providing liquidity services to the banking sector, as stressed by Woodford (1990). According to this view, private agents are liquidity constrained insofar as they cannot pledge the entire future income stream from profitable projects in order to obtain external finance. It is the highly liquid claim on government bonds that enables these constrained firms to obtain additional external funds to increase the size of their portfolio. The resulting non-Ricardian effects of government debt are usually attributed with welfare improvements, since an expansion of government borrowing increases the amount of securities available to liquidity constrained firms as in Holmström \& Tirole (1998) or Gorton \& Ordoñez (2013). However, this body of literature typically assumes that the government can perfectly commit to repay its outstanding debt. Recent events in the euro area have illustrated that this is not necessarily the case. In this paper, we allow for limited enforcement of government

\footnotetext{
${ }^{5}$ Note that no bailout of the financial sector is needed in this set-up to amplify sovereign risk, contrary to the framework of Acharya et al. (2014).
} 
debt that turns liquidity services from government securities into a state dependent general equilibrium outcome.

There have been a number of recent studies on the bank-sovereign link, mostly in non-stochastic models without reference to the business cycle. Within this literature, we are closest to Brutti (2011), Bolton \& Jeanne (2011), and Niemann \& Pichler (2013) who also account for a liquidity role for government bonds under sovereign risk. We extend this strand of literature by providing a quantification of the liquidity channel in a calibrated and simulated framework at the backdrop of the European sovereign debt crisis. Further, we are more specific on the propagation mechanism by structurally modelling an interbank market. This gives rise to several channels that have been discussed by policymakers during the crisis.

The spillover mechanism from sovereign risk to financial intermediaries is related to the bank capital channel that also creates an ex post penalty from sovereign default. Gennaioli et al. (2014) propose a model where the size of the default penalty is a function of the quality of domestic financial institutions, which allow domestic agents to increase the leverage of their balance sheets and to accumulate more government debt. Closely related is the analysis by Sandleris (2014). Acharya \& Rajan (2013) study a setting where government myopia helps to overcome the enforcement problem in the presence of endogenous default penalties. Short-termism induces policymakers to service debt today, whereas the adverse consequences of a write-down on the domestic financial system are shifted to the next political generation. Padilla (2013) proposes a stochastic model of optimal sovereign default with an endogenous default penalty due to a bank capital channel that is calibrated to the case of Argentina in 2001. The liquidity channel analysed here separates from the bank capital channel in that it induces an ex ante cost of sovereign risk which is important for the dynamic and quantitative results as it lowers the penalty and renders sovereign debt fragile even in the presence of high endogenous penalties.

Third, the framework features bond market trading that gives rise to simultaneous domestic and external debt positions in equilibrium. This is novel in the quantitative literature on sovereign default, which has so far focused on either external or domestic debt. ${ }^{6}$ Both the bank-sovereign link and the possibility of bond market trading affect default incentives and aggregate fluctuations through domestic accumulation of government securities. Since the government cannot discriminate between individual bond holders, bond market trading gives rise to non-penalty related incentives to repay external creditors, as the undesirable consequences of defaulting on domestic bond holders are internalised, similar to the political economy model of external and domestic sovereign debt by Guembel \& Sussman (2009). More generally, the bond market in our framework works in support of the repayment equilibrium and is therefore in line with the secondary bond market hypothesis developed by Broner et al. (2010).

The next section presents a novel set of stylised facts regarding sovereign risk and interbank markets in the euro area and discusses its parallels with business cycles in emerging markets. Section 3 contains a detailed description of the model. We discuss

\footnotetext{
${ }^{6}$ Technical motives might be the main reason for this neglect, as the global solution technique restricts the amount of endogenous state variables. At the same time, this is surprising as Reinhart \& Rogoff (2011) document that domestic public debt ranges between 40 and 80 percent of total public debt in a broad sample of advanced and emerging market countries.
} 
the model mechanics of the bank-sovereign link and spillovers to feasible allocations in Section 4. Section 5 documents the quantitative results and the final section concludes.

\section{Stylized facts on the bank-sovereign link in the euro area}

In this section we highlight three stylized facts about the European sovereign debt crisis. The first stylized fact focuses on the bank-sovereign channel in the euro area in the light of structural changes in bank financing patterns. As a consequence of the global financial crisis, European interbank short-term funding increasingly shifted from unsecured to secured (repo) interbank markets (European Central Bank 2012). From the peak volume of unsecured lending traded in 2007, total market turnover shrank by more than 30 percent in the four years through 2011 (Figure 1a). Over the same time period, the repo market was comparatively stable such that it developed into the major interbank market for wholesale funding (European Central Bank 2013). The behavioural changes undergoing bank funding structures in Europe since the burst of the subprime bubble were primarily related to an elevated level of counter-party risk. In the presence of asymmetric information about banks' idiosyncratic risk characteristics, collateral is a way to overcome agency problems underlying the interbank market. In a nutshell, a repo agreement replaces the counter-party default risk by the less likely event that the counter-party defaults and, simultaneously, the underlying collateral looses its value. For this reason, collateral used in private repo markets are usually high quality and liquid assets. In fact, more than 90 percent of collateral assets in European repo arrangements are securities backed by central governments (ICMA 2013).

With an intensification of the euro area debt crisis in the course of 2009-10, government securities from countries under an assistance programme were no longer accepted in European repo markets (Figure 1b). ${ }^{7}$ The increase in sovereign default risk triggered an adverse collateral channel at a time when structural shifts toward more secured funding were taking place in the European banking sector. ${ }^{8}$ As a result, banks in countries with fiscal stress underwent difficulties in tapping wholesale funding markets (fact 1). Some countries suffered practically an interbank freeze for both, secured and unsecured funding, and had to revert to central bank liquidity (Figure 1c). ${ }^{9}$

In the second half of 2011, repo market conditions for remaining euro area countries under fiscal stress tightened as well, as repo rates against collateral issued in core and periphery member countries started to diverge (Figure 1d). Specifically, the spread between the EONIA swap rate and the general collateral (GC) repo rate from France and Germany turned negative in the second half of 2011, while they were surging in

\footnotetext{
${ }^{7}$ Financial sector rescue packages in October 2008 contributed to the initial increase in public sector default risk in the European sovereign debt crisis as documented by Ejsing \& Lemke (2011).

${ }^{8}$ Gorton \& Metrick (2012) find evidence that the U.S. financial crisis similarly unfolded through a "run on repo" markets, where previously as safe regarded assets where subject to re-evaluations of risk.

${ }^{9}$ Giannone et al. (2012) provide a detailed empirical analysis on how the ECB's non-standard monetary policy interventions were replacing private intermediation on the interbank market.
} 
Figure 1: The collateral channel of sovereign risk

(a) Interbank turnover

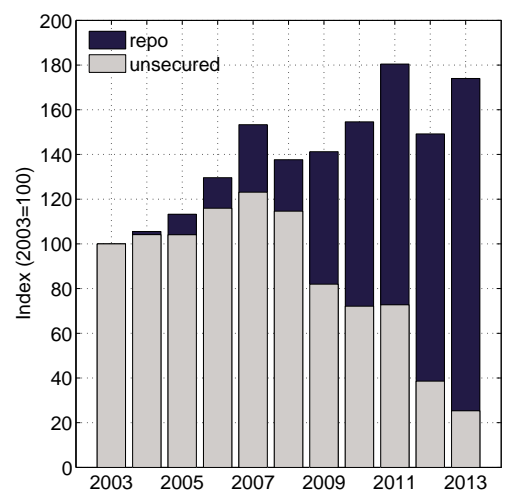

(c) Public intermediation

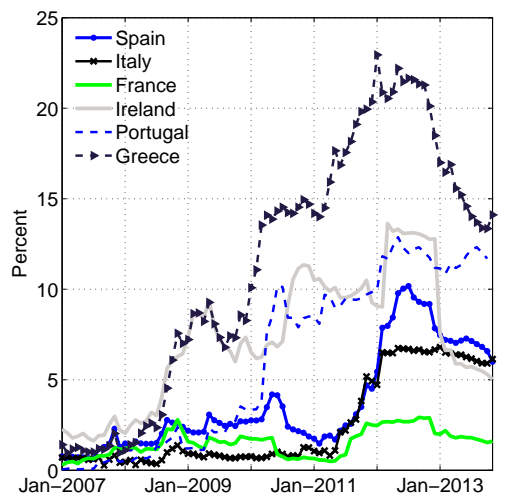

(b) Accepted collateral

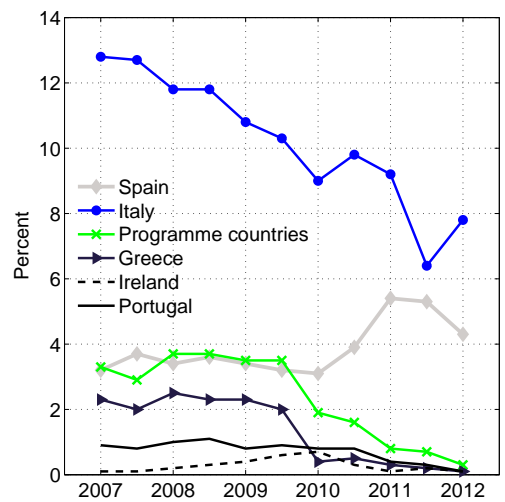

(d) GC repo rate

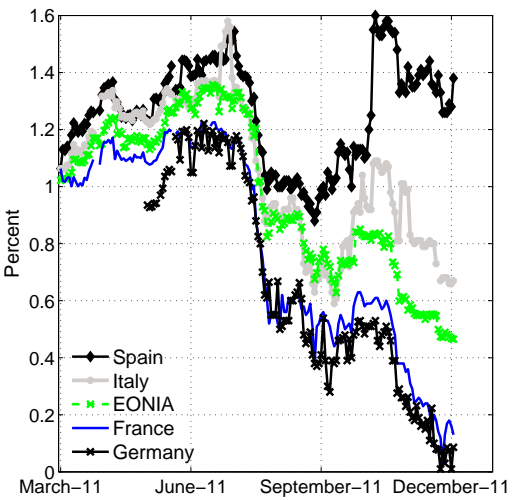

(e) Growth and default risk

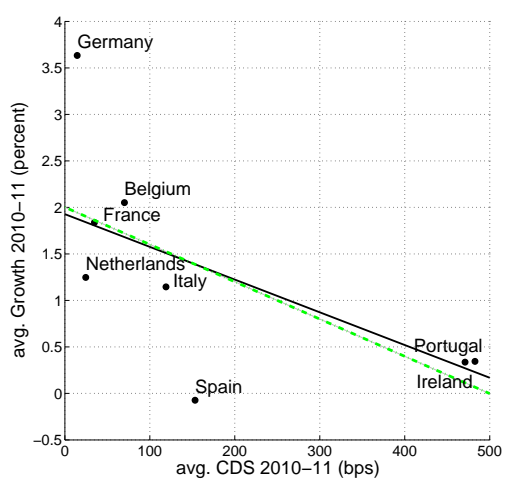

Notes: Panel (a) - Turnover formed as sum over lending and borrowing from ECB's money market survey. Panel (c) - Degree of public intermediation evaluated as percentage share of 'Lending to credit institutions related to monetary policy operations' and 'Other claims on euro area residents in euros' from NCB balance sheets over 'Total liabilities' from aggregate MFI balance sheets. Panel (e) - Dotted line includes data point for Greece. Source: ECB, ICMA, Bloomberg, NCBs, OECD, Thomson Reuters Datastream. 
Figure 2: Interest rates in the euro area
(a) Greece
(b) Portugal
(c) Ireland

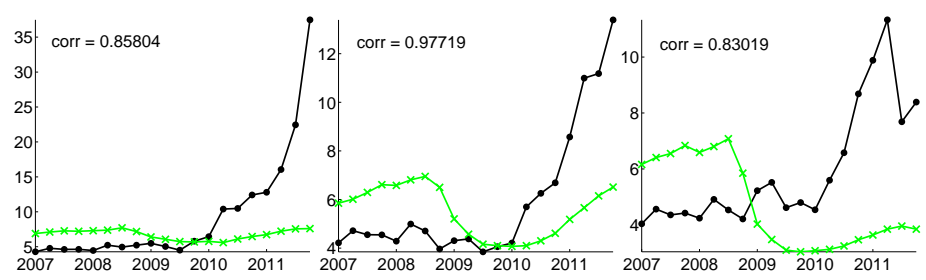

(d) Spain

(e) Italy

(f) Belgium

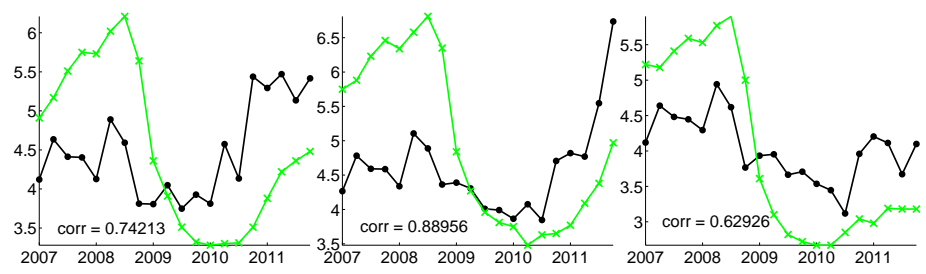

(g) Germany

(h) France

(i) Netherlands

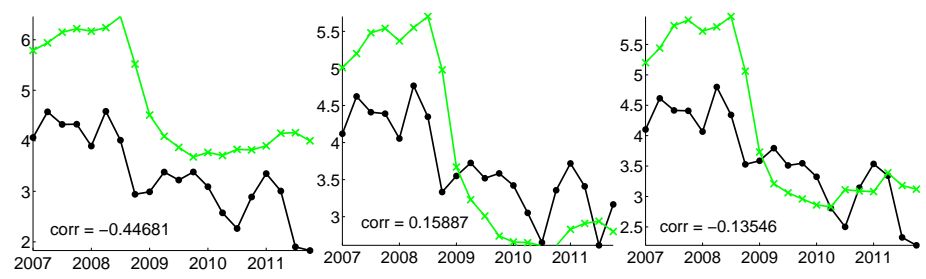

Note: Interest rates in levels. Black lines with dot $=$ Government bond yields from 10 year benchmark bond; Green lines with cross = bank lending rates to non-financial firms, maturity up to 1 year. Correlations computed over the period 2009q3-2011q4. Source: ECB, Thomson Reuters Datastream.

Spain and Italy. Thus, the lower credit quality of government securities translated into more costly liquidity services on repo markets. ${ }^{10}$

The second stylized fact relates to an amplification mechanism arising from the collateral channel: With a deteriorating collateral value of government bonds in the presence of a strong home-bias in government bond portfolios (Arslanalp \& Tsuda 2012), the collateral channel contributed to the overall increase in funding costs in the euro area periphery (BIS 2011). Higher funding costs for banks in the periphery translated into higher interest rates on loans to the non-financial sector.

The interest rates of the public and the private sector started to be highly correlated with the onset of the Greek debt crisis in the second half of 2009 (fact 2, Figure 2). This correlation was previously documented by Mendoza \& Yue (2012) in connection with foreign interest rates for a sample of 18 emerging market economies over the entire business cycle. In the context of the euro area sovereign debt crisis, it is the domestic

\footnotetext{
${ }^{10}$ This phenomenon is related to flight-to-liquidity effects as described by Beber et al. (2009) for European government bond markets. However, while Beber et al. focus on asset liquidity in terms of its resaleability, we concentrate on liquidity services generated through the collateral value of an asset.
} 
bank lending rate that turned out to be positively correlated with sovereign default risk due to the bank-sovereign link which unfolds, among others, via the collateral channel.

The third stylized fact is addressing the interaction of the bank-sovereign link with macroeconomic fluctuations. Overall economic performance seems to have played a major role in the further escalation of the sovereign debt crisis. Figure 1e) shows a strong negative correlation between average quarterly growth rates over the 2010 to 2011 period and average CDS yields. Countries in the euro area periphery in very deep recessions experienced particular strong increases in sovereign default risk ( fact 3). This comes as little surprise given that the sovereign debt crisis developed into a systemic crisis. In the next section, we present a model that explains the stylized facts presented here by emphasising the collateral role of government securities in the financial system of an economy.

\section{Model environment}

\subsection{Overview}

The core of the model is a small open economy real business cycle model with a benevolent government subject to a limited commitment friction that gives rise to endogenous risk of sovereign default. The novel block is a heterogeneous banking sector that intermediates financial resources on domestic interbank and credit markets, thereby providing working capital loans to non-financial firms. Government bonds are used as collateral on the interbank market.

Time is infinite and discrete $t=(0,1,2, \ldots)$. The state space is given by $s \in$ $\left(B_{t}, B_{t}^{D}, A_{t}\right)$, where $B_{t}$ denotes total outstanding government debt, $B_{t}^{D}$ is domestically accumulated collateral on bank balance sheets, and $A_{t}$ an exogenous aggregate productivity state. Endogenous states $\epsilon_{t} \in\left(B_{t}, B_{t}^{D}\right)$ are given from period $t-1$ decisions. When the productivity shock realizes at the beginning of the period, the government takes its binary default decision $\delta_{t} \in\{0,1\}$ as the outcome of an optimization problem. In case of default, the economy falls into financial autarky with a stochastic probability of re-entering capital markets in period $t+1$. There is no debt trading in the autarky state. In the no-default equilibrium, domestic banks intermediate funds on interbank and credit markets to non-financial firms. Interbank lending is subject to financial frictions that interact with sovereign risk. For simplicity, we assume that lending from banks to firms occurs without frictions with non-contingent debt contracts. Primary and secondary bond market trading evolves simultaneously and determines the asset position of the government and banks in the consecutive period. $^{11}$

\footnotetext{
${ }^{11}$ We use bond market trading and secondary bond market trading interchangeably in this paper. A detailed overview on the timing of events is provided in the Appendix B.
} 


\subsection{Households}

A representative household derives utility from consumption and leisure. It owns domestic firms and banks while receiving profits and dividends in a lump sum fashion at the end of each period. The optimization problem of the household is static, choosing optimal period $t$ consumption and labour supply. We assume that the household consumes all available resources according to its flow budget constraint. Consumption smoothing over time can only be obtained by government transfers. We thereby follow the motivation typically provided for government transfers through international borrowing in the literature on optimal sovereign default. ${ }^{12}$ The household maximizes lifetime utility subject to a budget constraint

$$
\begin{array}{ll} 
& \max _{\left\{C_{t}, L_{t}\right\}} E_{t} \sum_{t=0}^{\infty} \beta^{t} U\left(C_{t}, 1-L_{t}\right), \\
\text { s.t. } & C_{t}=W_{t} L_{t}+\Pi_{t}+D_{t}+T_{t},
\end{array}
$$

where $E_{t}$ is the rational expectations operator, $C_{t}$ denotes consumption and $\beta$ is the discount factor. Time available to households is normalised to one unit such that $1-L_{t}$ and $L_{t}$ denote leisure and hours worked, respectively. The utility function $U: \mathbb{R}_{+}^{2} \rightarrow \mathbb{R}$ is twice continuously differentiable in both its arguments, and satisfies $U_{C}>0, U_{C C}<0, U_{L}<0$ and $U_{L L}<0$. $W_{t}$ is the real wage that is exogenous from the perspective of the representative household. $\Pi_{t}$ denote non-financial firms' profits, $D_{t}$ are banking sector dividend payments, and $T_{t}$ lump-sum government transfers or taxes. Labour supply is pinned down by the marginal rate of substitution between consumption and labour equated with the real wage:

$$
-\frac{U_{L}\left(C_{t}, 1-L_{t}\right)}{U_{C}\left(C_{t}, 1-L_{t}\right)}=W_{t}
$$

\subsection{Non-financial firms}

There is a competitive non-financial sector in the economy which produces a tradeable final good with a Cobb-Douglas production function. Profits are maximized by the choice of labour input at a constant capital stock $K$. A fraction $\eta>0$ of the wage bill needs to be paid to workers up-front at the beginning of each period prior to production. Since non-financial firms are liquidity constrained and do not have the possibility to save, they obtain credit $\kappa_{t}$ from domestic banks at the endogenous interest rate $r_{t}^{\kappa}{ }^{13}$ The representative non-financial firm's profit maximisation problem

\footnotetext{
${ }^{12}$ Among others, Aguiar \& Gopinath (2006) and Arellano (2008) use household consumption smoothing to motivate government borrowing. An alternative motivation for international borrowing is to smooth government expenditures, see Cuadra et al. (2010).

${ }^{13}$ The implied assumption is that domestic firms do not access international capital markets for credit. This seems justified by the fact that (i) firms in the euro area are typically bank financed, and (ii) the banking sector is predominantly domestically owned (European Central Bank 2013).
} 
takes the form:

$$
\begin{array}{ll} 
& \max _{\left\{L_{t}, \kappa_{t}\right\}} \Pi_{t} \\
\text { with } & \Pi_{t}=Y_{t}-W_{t} L_{t}-\kappa_{t} r_{t}^{\kappa}, \\
& Y_{t}=e^{A_{t}} K^{\alpha} L_{t}^{(1-\alpha)}, \\
\text { s.t. } & \kappa_{t} \geq \eta W_{t} L_{t} .
\end{array}
$$

Since working capital is costly, the constraint in equation (4) holds with equality in equilibrium. The resulting first-order condition for labour demand equates the marginal product of labour to the marginal cost which consists of the wage rate plus financing costs from working capital borrowing. ${ }^{14}$

$$
(1-\alpha) e^{A_{t}} K^{\alpha} L_{t}^{-\alpha}=W_{t}\left(1+\eta r_{t}^{\kappa}\right)
$$

The only aggregate uncertainty is due to a stationary autoregressive process of order one for total factor productivity $A_{t}$

$$
A_{t}=\rho A_{t-1}+\varepsilon_{t}
$$

with $0<\rho<1$ and white noise process $\varepsilon_{t} \sim \mathcal{N}\left(0, \sigma_{\varepsilon}^{2}\right)$.

\subsection{Banks}

Financial intermediation is motivated by the need for external finance of the nonfinancial sector. ${ }^{15}$ The banking sector is assumed to be of measure one and populated by an infinite number of banks $i \in[0,1]$. Banks enter period $t$ with previously accumulated government bonds $B_{t}^{D}$ as well as a constant and exogenous amount $N$ of household deposits. From an accounting identity perspective, it follows that collateral assets form bank equity $K_{t}^{b}$. Banks are endowed with retail deposits $N$ in the initial period and pass them from one period to the next as cash holdings $C_{t}^{m} .{ }^{16}$

We follow the idea of temporary market segmentation in order to motivate an interbank market (e.g. Gertler \& Kiyotaki, 2011). Banks exhibit within-period heterogeneity of two different types $\tau \in\{p, u\}$. At an exogenously given probability $\pi^{p}$, a bank turns into a productive bank of type $p$. This bank is matched with a non-financial firm to which it is able to extend credit $\kappa_{t}$ at the endogenously determined interest rate $r_{t}^{\kappa}$. To this end, bank $p$ uses its own liquid liabilities $N^{p}$. Additionally, it can borrow funds at the domestic interbank market $M_{t}$. Working capital and interbank funding are intra-period loans that mature at the end of period $t$.

In case a bank borrows from the interbank market, we assume that it accumulates

\footnotetext{
${ }^{14}$ See Uribe \& Yue (2006) for an extensive discussion of the interest rate on working capital as an intra-period loan contract.

${ }^{15}$ We abstract from a microfoundation of the intermediary. Diamond (1984) provides a theory for the existence of financial intermediaries due to a cost advantage in monitoring.

${ }^{16}$ As the focus of the paper is the adjustment of bank balance sheets through changes in wholesale funding from the interbank market, we leave the adjustment of retail deposits for future research. Further, we are restricted in the amount of state variables due to the numerical solution method.
} 
excess reserves $R_{t}^{e}$. This captures the self-insurance motive against costly liquidity shortfall due to roll-over risk in reduced form, formally: ${ }^{17}$

$$
R_{t}^{e}=\frac{M_{t}}{\phi}
$$

with $\phi>1$. Demand for excess reserves induces a spread in the credit rate over bank funding costs, as they convey opportunity costs to productive banks.

A bank turns into an unproductive bank, or type $u$, with complement probability $\pi^{u}=1-\pi^{p}$. Type $u$ banks do not have the opportunity to provide loans to the nonfinancial sector. Instead, they offer their resources as interbank loans to type $p$ banks at the interbank market rate $r_{t}^{M}$. As productive banks are short of funding in equilibrium for many states of the world, the interbank market gives rise to a reallocation of funds across banks.

Finally, banks of both types may store cash within a period in the central bank's deposit facility, $R_{t}^{d, \tau}$. Excess reserves and cash stored in the deposit facility are remunerated at a constant exogenous rate $r^{R}$. Bank balance sheets are summarized in Table 1, where total reserves are denoted by $R_{t}^{\tau}$.

Table 1: Bank balance sheets

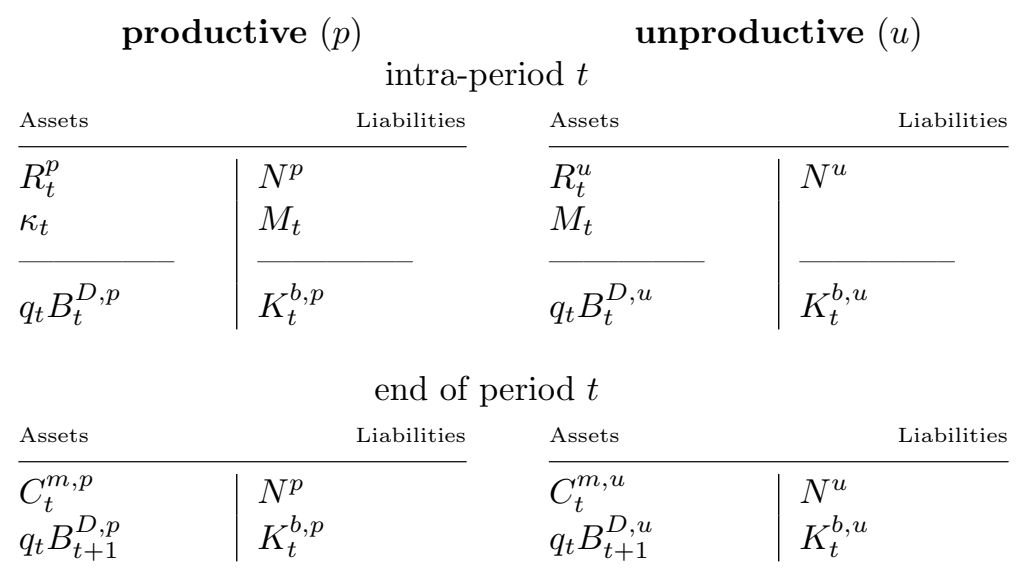

Interbank loans need to be collateralised at a constant haircut of size $\chi{ }^{18}$ The only available collateral in the model economy are government securities which take the form of one-period discount bonds. ${ }^{19}$ The government cannot commit to repay. A bond issued in period $t-1$ contains a promise by the government to repay one unit of

\footnotetext{
${ }^{17}$ However, we do not model a maturity mismatch that would give rise to roll-over risk on the interbank market here. Costly liquidity shortfall in the banking sector under stochastic liability withdrawals has been modelled in Poole (1968) or Baltensperger (1980), among others. Chari et al. (1995) use a similar reduced form for demand in excess reserves in a macro setting.

${ }^{18}$ The collateral requirement on the interbank market is introduced ad hoc for simplicity. It is possible to derive an incentive compatibility constraint similar to equation (8) from an agency problem. One possibility is that the borrowing bank $p$ is limited to pledge future income for repayment on its liabilities $M_{t}$ to type $u$ banks due to moral hazard as shown by Holmström \& Tirole (1998).

${ }^{19}$ This assumption is in line with empirical regularities in the euro area as discussed in Section 2. Further, Krishnamurthy \& Vissing-Jorgensen (2012) document that US-Treasuries are close substitutes to money due to their high liquidity and safety. With this property, government debt features low information sensitivity which makes it a preferred choice for collateral (Dang et al. 2013).
} 
the numeraire good in period $t$, conditional on not defaulting. Let $\delta_{t} \in\{0,1\}$ denote the period $t$ default decision of the government, where repayment is given by $\delta_{t}=0$. The government's default decision is taken as exogenous from the bank perspective. Further, let $B_{t}^{D, \tau}$ denote collateral accumulated on bank balance sheet of type $\tau$. Then, the period $t$ value of government bonds held by banks is $\left(1-\delta_{t}\right) B_{t}^{D, \tau}$ such that the collateral constraint takes the form:

$$
M_{t} \leq \frac{\left(1-\delta_{t}\right) B_{t}^{D, p}}{\chi}
$$

We use the result of Barro (1976) who shows that the price for a collateralised debt contract accounts for the quality of the underlying collateral. ${ }^{20}$ To this end, let $\Psi\left(q_{t}\right)$ denote a risk premium on secured interbank contracts that is assumed to be decreasing in the price of government bonds $q_{t}$.

Banks purchase government securities on bond markets at price $q_{t}$. In line with the literature, we define government assets as net borrowing of the sovereign, $B_{t}<0$. Government bonds are either held domestically by the banking sector, or internationally by financial investors, $B_{t}^{*}$. The market clearing condition on the bond market reads

$$
B_{t+1}+B_{t+1}^{D}+B_{t+1}^{*}=0, \quad \text { with } B_{t+1}^{D}, B_{t+1}^{*} \geq 0
$$

such that $-q_{t} B_{t+1}^{*}=q_{t}\left(B_{t+1}+B_{t+1}^{D}\right)$ denotes the net foreign asset position of the economy.

Each bank maximizes discounted expected lifetime dividend payments to the representative household using the bank discount factor $\beta^{b}{ }^{21}$

$$
\max E_{t}\left[\sum_{j=0}^{\infty} \beta^{b^{j}} D_{t+j}^{\tau}\right],
$$

where the choice variables depend on the idiosyncratic realization of types $\tau \in\{p, u\}$. We exploit the recursive structure of the model to rewrite the problem in Bellman form. The maximization problem for a bank of type $p$ reads

$$
\mathcal{W}^{p}\left(B_{t}, B_{t}^{D}, A_{t}\right)=\max _{\left\{B_{t+1}^{D, p}, \kappa_{t}, M_{t}, R_{t}^{e}, R_{t}^{d, p}\right\}}\left\{D_{t}^{p}\left(B_{t}, B_{t}^{D}, A_{t}\right)+\beta^{b} E_{t}\left[\mathcal{W}\left(B_{t+1}, B_{t+1}^{D}, A_{t+1}\right)\right]\right\},
$$

with dividends defined as

$$
D_{t}^{p}=\left(1-\delta_{t}\right) B_{t}^{D, p}+\left(1+r_{t}^{\kappa}\right) \kappa_{t}-\left(1+r_{t}^{M}\right) M_{t}+\left(1+r^{R}\right) R_{t}^{p}-\left(1-\delta_{t}\right) \tilde{q}_{t} B_{t+1}^{D, p}-N^{p} .
$$

\footnotetext{
${ }^{20}$ In Barro (1976), contract parties account for the effective interest rate by internalising the probability of collateral exchange in the event of a counter-party default. However, allowing for equilibrium interbank default that leads to the exchange of collateral is beyond the scope of this paper.

${ }^{21}$ Using the stochastic discount factor of the representative household would distort the collateral accumulation decision of banks, since models with sovereign default feature low values for $\beta$ to account for default in equilibrium, see Mendoza \& Yue (2012).
} 
The bank $p$ objective function is subject to (7), (8), and the following constraints:

$$
\begin{gathered}
N^{p}+M_{t}=\kappa_{t}+R_{t}^{p} \\
R_{t}^{p}=R_{t}^{e}+R_{t}^{d, p} \\
R_{t}^{d, p}, D_{t}^{p} \geq 0
\end{gathered}
$$

The flow of funds constraint (11) illustrates that an increase in credit $\kappa_{t}$ beyond the liquid resources $N^{p}$ requires interbank borrowing. Total reserves held by a productive bank $R_{t}^{p}$ are either excess reserves, or cash stored in the deposit facility (12). The non-negativity constraint on the deposit facility (13) implies that there is no direct funding available from the central bank.

The collateral constraint (8) constitutes an occasionally binding borrowing constraint. Productive banks can obtain additional funding only up to a multiple $\chi$ of the market value of government securities currently on their balance sheet. As financial sector holding of government debt is an endogenous state variable, this constraint establishes the inter-temporal dimension of the banks' problem. Particularly, banks are trading-off dividend payments today against future dividend payments. The bank cannot purchase more public securities than there are cash-flows available in period $t$ (13).

The maximization problem of type $u$ banks takes the form

$$
\mathcal{W}^{u}\left(B_{t}, B_{t}^{D}, A_{t}\right)=\max _{\left\{B_{t+1}^{D, u}, M_{t}, R_{t}^{d, u}\right\}}\left\{D_{t}^{u}\left(B_{t}, B_{t}^{D}, A_{t}\right)+\beta^{b} E_{t}\left[\mathcal{W}\left(B_{t+1}, B_{t+1}^{D}, A_{t+1}\right)\right]\right\}
$$

with dividends defined as

$$
D_{t}^{u}=\left(1-\delta_{t}\right) B_{t}^{D, u}+\left(1+r_{t}^{M}\right) M_{t}+\left(1+r^{R}\right) R_{t}^{u}-\left(1-\delta_{t}\right) \tilde{q}_{t} B_{t+1}^{D, p}-N^{u}
$$

subject to the constraints

$$
\begin{gathered}
N^{u}=M_{t}+R_{t}^{u} \\
R_{t}^{u}=R_{t}^{d, u} \\
R_{t}^{d, u}, D_{t}^{u} \geq 0
\end{gathered}
$$

Equation (15) constitutes the flow of funds constraint. Bank $u$ reserves are defined by its use of the central bank deposit facility (16). As in the problem of type $p$ banks, additional funds from the central bank are not available, and collateral purchases are constrained by the non-negativity constraint on dividends (17).

As period $t+1$ types are unknown and probabilities are identically and independently distributed, expected future dividend payments are formed using the unconditional probability for each type in the consecutive period:

$$
E_{t}\left[\mathcal{W}\left(B_{t+1}, B_{t+1}^{D}, A_{t+1}\right)\right]=E_{t}\left[\pi^{p} \mathcal{W}^{p}\left(B_{t+1}, B_{t+1}^{D}, A_{t+1}\right)+\pi^{u} \mathcal{W}^{u}\left(B_{t+1}, B_{t+1}^{D}, A_{t+1}\right)\right]
$$

Forming the Lagrangian for both types of banks, the first-order conditions for credit, 
excess reserves and collateral of productive banks read ${ }^{22}$

$$
\begin{gathered}
r_{t}^{\kappa}=r^{R}+\mu_{t}^{p} \\
r_{t}^{\kappa}=r_{t}^{M}+\frac{r_{t}^{\kappa}-r^{R}}{\phi}+\lambda_{t} \chi \\
\tilde{q}_{t}=\beta^{b} E_{t}\left[\mathcal{W}_{B^{D}}\left(B_{t+1}, B_{t+1}^{D}, A_{t+1}\right)\right]+\mu_{t}^{D, p},
\end{gathered}
$$

Optimal supply of working capital credit from (18) implies that the type $p$ bank wants to increase its lending to non-financial firms as long as it earns at least a return of $r^{R}$, which constitutes the opportunity investment within period $t . \mu_{t}^{p}$ denotes the Lagrange multiplier on the flow of funds constraint. The optimal amount of wholesale funding (19) accounts for the cost of funding $r_{t}^{M}$ and the foregone profits due to additional excess reserves which lower funds available for credit by $1 / \phi$. The Lagrange multiplier on the collateral constraint $\lambda_{t}$ captures whether further interbank borrowing is feasible. Equation (20) is the pricing equation for government bonds at secondary bond markets which is discussed below.

Optimization of type $u$ banks yield as first-order conditions

$$
\begin{gathered}
r_{t}^{M}=r^{R}+\Psi\left(q_{t}\right)+\mu_{t}^{u}, \\
\tilde{q}_{t}=\beta^{b} E_{t}\left[\mathcal{W}_{B^{D}}\left(B_{t+1}, B_{t+1}^{D}, A_{t+1}\right)\right]+\mu_{t}^{D, u},
\end{gathered}
$$

Optimal supply of interbank loans in (21) states that the interbank rate $r_{t}^{M}$ makes type $u$ banks indifferent between investing in excess reserves or interbank loans. In equilibrium, unproductive banks are competing for loan demand on the interbank market such that $\mu_{t}^{u}=0$ and $r_{t}^{M}=r^{R}+\Psi\left(q_{t}\right)$. The bond pricing equation (22) is discussed below.

The complementary slackness conditions for the inequality constraints of the banking sector are the following set of equations

$$
\begin{aligned}
\lambda_{t}\left(0-\chi M_{t}+\left(1-\delta_{t}\right) B_{t}^{D, p}\right) & =0 & & \\
\mu_{t}^{\tau}\left(0+R_{t}^{d, \tau}\right) & =0 & & \forall \tau \in\{p, u\} \\
\mu_{t}^{D, \tau}\left(0+D_{i, t}^{\tau}\right) & =0 & & \forall \tau \in\{p, u\} \\
\lambda_{t}, \mu_{t}^{\tau}, \mu_{t}^{D, \tau} & \geq 0 & & \forall \tau \in\{p, u\}
\end{aligned}
$$

where $\lambda_{t}, \mu_{t}^{\tau}, \mu^{D, \tau} \forall \tau \in\{p, u\}$ denote the Lagrange multipliers on the collateral constraint, the non-negativity constraints on central bank deposits and dividends, respectively.

In order to arrive at the aggregate equilibrium allocations in the model economy across banking types, we use the following proposition:

Proposition 1. (Aggregation) Under the assumption of equal collateral holdings of banks in the initial period $t=0$, there exists a representative bank for each type $\tau \in\{p, u\}$ such that the equilibrium allocations can be derived from the representative

\footnotetext{
${ }^{22}$ See Appendix $\mathrm{C}$ for a detailed derivation of the results.
} 
bank. In particular, the following relationship holds:

$$
\sum_{i=1}^{\pi^{\tau}} B_{t, i}^{D, \tau}=\pi^{\tau} B_{t}^{D}, \quad \tau \in\{p, u\}
$$

Proof. See Appendix A.

From Proposition 1 follows that no subscripts for individual banks are required in equations (10)-(13), and (14)-(17). Aggregate dividend payments to households are obtained by summing over bank types $D_{t}=D_{t}^{p}+D_{t}^{u}$ and, accordingly, for central bank reserves $R_{t}=R_{t}^{p}+R_{t}^{u}$.

Turning now to the dynamic part of the bank decision problem, note that the pricing decisions (20) and (22) for collateral at government bond markets are identical across bank types due to the independent and identical probability of turning into a productive bank in the consecutive period. The envelope condition for $\mathcal{W}_{B^{D}}\left(B_{t+1}, B_{t+1}^{D}, A_{t+1}\right)$ yields

$$
\begin{aligned}
\mathcal{W}_{B^{D}}\left(B_{t+1}, B_{t+1}^{D}, A_{t+1}\right) & =\pi^{p}\left(1-\delta_{t+1}+\lambda_{t+1}\right)+\pi^{u}\left(1-\delta_{t+1}\right)+\mu_{t}^{D} \\
& =1-\delta_{t+1}+\pi^{p} \lambda_{t+1}+\mu_{t}^{D}
\end{aligned}
$$

such that the pricing equation for collateral assets from both types of banks takes the form

$$
\tilde{q}_{t}=\beta^{b}\left(1-\pi_{t}^{\delta}\right)+\pi^{p} \beta^{b} E_{t}\left(\lambda_{t+1}\right)+\mu_{t}^{D}+\mu_{t}^{B^{D}},
$$

where $E_{t}\left(\delta_{t+1}\right)=\pi_{t}^{\delta}$ denotes the default probability of government bonds in period $t+1$, evaluated at the period $t$ information set. The pricing equation (27) is composed of four parts. First, the bank prices the bond according to its discounted expected pay-offs from repayment in period $t+1$. Second, with probability $\pi^{p}$ a bank will be of type $p$ in period $t+1$ and, hence, is able to increase lending to non-financial firms if it holds additional collateral. We restate this analytical result in the following proposition:

Proposition 2. (Liquidity premium) Due to liquidity services derived from holding government bonds as collateral on the interbank market, banks' asset pricing equation on public debt yields a liquidity premium, denoted as $\hat{\lambda}_{t}$, in the form:

$$
\hat{\lambda}_{t} \equiv \pi^{p} \beta^{b} E_{t}\left(\lambda_{t+1}\right)
$$

Proof. See Appendix A.

The two last terms in equation (27) relate to corner solutions on the government bond market in case of binding constraints, either due to non-negative dividend payments, or due to total outstanding public securities from (9). Banks take the total outstanding amount of government debt as given and may run into the problem of low supply of government bonds such that $\mu_{t}^{B^{D}}>0$.

As international investors have unlimited funds, banks take the price for public securities $q_{t}$ as given. The following proposition describes the supply and demand of government bonds from international investors: 
Proposition 3. Risk-neutral international investors exhibit a perfectly elastic supply and demand function of government bonds on secondary bond markets at price $q_{t}$.

Proof. See Appendix A.

Let $\mathcal{F}\left(B_{t}, B_{t}^{D}, A_{t}\right)=B_{t+1}^{D *} \mid B_{t+1}$ denote the demand function for domestically held debt conditional on the total amount of newly issued government securities. Demand from banks is pinned down by the no-arbitrage condition from equation (27) while taking prices as given from Proposition 3, hence

$$
\begin{gathered}
\tilde{q}_{t}-q_{t}=0 \\
\Leftrightarrow \quad \beta^{b}\left(1-\pi_{t}^{\delta}\right)+\pi^{p} \beta^{b} E_{t}\left(\lambda_{t+1}\right)+\mu_{t}^{D}+\mu_{t}^{B^{D}}-q_{t}=0,
\end{gathered}
$$

Banks purchase government debt up to the amount where they expect zero liquidity premium on additional collateral holding, if unconstrained by their respective flow budget constraint or the short-selling constraint.

Figure 3: Bond market equilibria

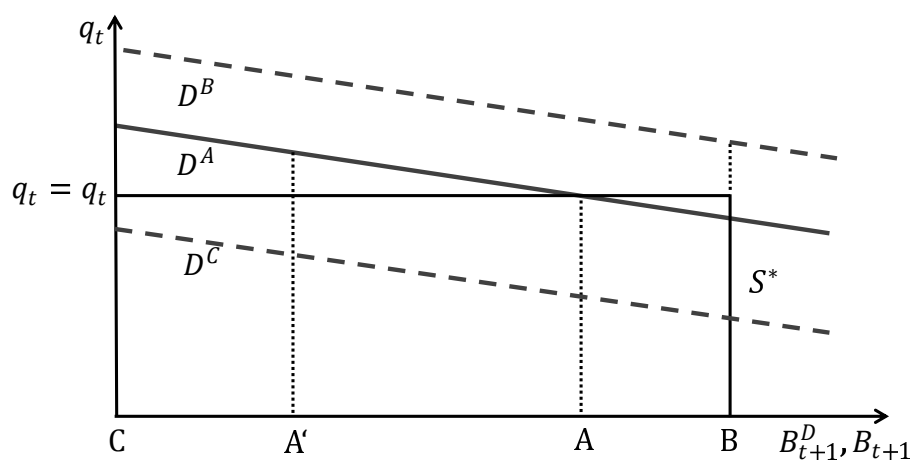

Figure 3 illustrates the possible equilibria on the market for government debt. International investors' supply curve is perfectly elastic at the market price $q_{t}$ and given by $S^{*}$ (Proposition 3). Domestic banks take the bond price as given and have a downward sloping demand for collateral $\left(D^{A}\right)$, which is due to a decreasing expected liquidity value for collateral, $\frac{\partial^{2} \hat{\lambda_{t}}}{\partial B_{t+1}^{D}}<0$. An interior solution on the interval $B_{t+1}^{D} \in\left(0, B_{t+1}\right)$ is found if $\tilde{q}_{t}=q_{t}$ and no constraint is binding $(A)$, or if the accumulation of collateral is limited by the non-negativity requirement for dividend payments $\left(A^{\prime}\right)$. Corner solutions are realized if demand for collateral assets is exceeding total supply $(B)$. In this case, total public debt is held domestically. The opposite case is given if domestic banks have a very low expected collateral value in the consecutive period such that $\tilde{q}<q(C)$.

\subsection{Central bank}

A central bank collects bank deposits and excess reserves from the domestic banking system. All reserves are remunerated at a fixed and exogenously given rate $r^{R}$. To keep 
a clear focus of the analysis, we do not consider any form of central bank intervention. Period $t$ central bank profits amount to

$$
\Pi_{t}^{c b}=-R_{t} r^{R}
$$

which are transferred lump-sum to the government.

\subsection{Partial equilibrium}

We need to define two types of partial equilibria. In the repayment equilibrium absent sovereign default, the partial equilibrium consists of market clearing quantities and prices for the labour market, credit market, and the interbank market variables $\left\{L_{t}, W_{t}, r_{t}^{\kappa}, r_{t}^{M}, \kappa_{t}, M_{t}, R_{t}^{e}, R^{d, \tau}, R_{t}^{\tau}, \lambda_{t}, \mu_{t}^{\tau}\right\}$. Taking as given the aggregate state $s \in\left(B_{t}, B_{t}^{D}, A_{t}\right)$ and the price of government debt $q_{t}\left(B_{t+1}, B_{t+1}^{D}, A_{t}\right)$, the equations (2), (4), (5), (7), (8), (11), (12), (13), (15), (16), (17), (18), (19), and (21), in combination with the complementary slackness conditions (23), (24), (26) solve the non-linear system.

The inter-temporal collateral decision is derived as a reaction function conditional on the government decision on total outstanding debt, $\mathcal{F}\left(B_{t}, B_{t}^{D}, A_{t}\right)$. The unknowns $\left\{B_{t+1}^{D *}, \mu_{t}^{D}, \mu_{t}^{B^{D}}\right\}$ are obtained from equations (25), (26), and (27). Finally, dividend payments are derived from (10) and (14).

In the partial equilibrium under sovereign default, interbank market trading breaks down as $q_{t}=0$, such that $M_{t}=R_{t}^{e}=0$ follows jointly from the collateral constraint and the liquidity preference. Hence, $r_{t}^{M}$ and $\lambda_{t}$ remain undefined and all resources of unproductive banks are deposited at the central bank, $R_{t}^{d, u}=N^{u}$. The solution to the remaining partial equilibrium variables $\left\{L_{t}, W_{t}, r_{t}^{\kappa}, \kappa_{t}, R_{t}^{d, p}, R_{t}^{p}, \mu_{t}^{p}\right\}$ is given by equations (2), (4), (5), (11), (12), (13), (18), in combination with the complementary slackness conditions (24), (26) for $\tau=p$.

\subsection{Government}

There is a benevolent government in analogy to Eaton \& Gersovitz (1981) that cannot commit to repay its debt. Specifically, the government chooses to default on the total amount of outstanding debt if this is welfare maximizing in terms of household utility given the aggregate state of the economy $s \in\left(B_{t}, B_{t}^{D}, A_{t}\right)$. We look at equilibria where the government cannot discriminate between foreign and domestic bond holders when defaulting. Technically, the optimal default decision consists of maximizing the value function

$$
\mathcal{V}_{t}\left(B_{t}, B_{t}^{D}, A_{t}\right)=\max _{\delta_{t} \in\{0,1\}}(1-\delta) V_{t}^{n d}\left(B_{t}, B_{t}^{D}, A_{t}\right)+\delta_{t} V_{t}^{d}\left(B_{t}, B_{t}^{D}, A_{t}\right),
$$

where $V_{t}^{n d}, V_{t}^{d}$ denote the value of repayment and default, respectively.

In case the government decides to repay its debt obligations, it borrows from capital markets by selling one period discount-bonds $B_{t+1}<0$ at the market price $0<q_{t}<1$. This bond pays back $B_{t+1}$ units of consumption goods in period $t+1$, conditional on 
not defaulting. Government borrowing serves a consumption smoothing purpose for private households via direct transfer payments $T_{t}$ according to the implicit government flow budget constraint

$$
T_{t}=\Pi_{t}^{c b}+\left(B_{t}-q_{t} B_{t+1}\right)\left(1-\delta_{t}\right),
$$

where central bank profits $\Pi_{t}^{c b}$ from equation (28) are consolidated in the government budget constraint.

The government decides on its optimal debt policy and internalises the decentralised collateral decision of the financial sector by taking account of the reaction function $\mathcal{F}\left(B_{t}, B_{t}^{D}, A_{t}\right)$. Optimal new borrowing conditional on not defaulting maximizes the following value function

$$
\begin{aligned}
V_{t}^{n d}\left(B_{t}, B_{t}^{D}, A_{t}\right)= & \max _{\left\{C_{t}, B_{t+1}\right\}}\left\{U\left(C_{t}, 1-L_{t}\right)\right. \\
& \left.+\beta \int_{A_{t+1}} \mathcal{V}_{t+1}\left(B_{t+1}, B_{t+1}^{D}, A_{t+1}\right) f\left(A_{t+1}, A_{t}\right) d A_{t+1}\right\},
\end{aligned}
$$

subject to the aggregate resource constraint in the economy ${ }^{23}$

$$
\begin{aligned}
C_{t} & =e^{A_{t}} K^{\alpha} L_{t}^{1-\alpha}+\left(B_{t}+B_{t}^{D}\right)-q_{t}\left(B_{t+1}+B_{t+1}^{D}\right) \\
& =Y_{t}-B_{t}^{*}+q_{t} B_{t+1}^{*}
\end{aligned}
$$

and the set of partial equilibrium conditions under repayment as laid out in Section 3.6 .

The trade-off for the optimal government debt policy is implied in the latter equation, where benefits in terms of household utility from increases in net external debt need to be weighted against the spillovers to aggregate production. Specifically, the collateral channel introduces an ambiguous sign on the reaction of output to an increase in the total amount of outstanding debt. At very low levels of government debt, an expansion of public borrowing leads to an increase in securities available to the banking sector, thereby stimulating output. On the other side weighs the interaction of sovereign risk with financial frictions on the cost of working capital and output if the level of public debt turns risky from the perspective of bond holders.

The government internalizes these externalities of its borrowing decision, which might arise either from a drop in the bond price $q_{t}$ as a consequence of choosing high debt levels, or from an overall scarcity of collateral from choosing very low debt levels. Given that the government cannot remove the deep frictions inherent to the domestic financial sector, it achieves a constrained efficient outcome under the repayment regime.

In line with the literature, investors penalise the government for defaulting by forcing the economy into financial autarky with a stochastic probability $\theta>0$ of re-entering capital markets. When regaining market access, the economy starts with zero govern-

\footnotetext{
${ }^{23} \mathrm{~A}$ formal derivation of the aggregate resource constraint is provided in Appendix $\mathrm{C}$.
} 
ment bonds. The value of choosing default is defined by

$$
\begin{gathered}
V_{t}^{d}\left(B_{t}, B_{t}^{D}, A_{t}\right)=\max _{\left\{C_{t}\right\}}\left\{U\left(C_{t}, 1-L_{t}\right)\right. \\
\left.+\beta \int_{A_{t+1}}\left(\theta V_{t+1}^{n d}\left(0,0, A_{t+1}\right)+(1-\theta) V_{t+1}^{d}\left(0,0, A_{t+1}\right)\right) f\left(A_{t+1}, A\right) d A_{t+1}\right\}
\end{gathered}
$$

subject to the set of partial equilibrium conditions without interbank trading from Section 3.6 and the resource constraint under autarky:

$$
C_{t}=Y_{t}
$$

The default set $\Gamma_{t}^{\delta}$ is defined as the subset of the productivity state $A_{t}$ for which the value of defaulting is strictly higher than the value of repayment, given the endogenous state $\epsilon_{t} \in\left(B_{t}, B_{t}^{D}\right)$ :

$$
\Gamma_{t}^{\delta}\left(B_{t}, B_{t}^{D}\right)=\left\{A_{t} \in s: V_{t}^{d}\left(B_{t}, B_{t}^{D}, A_{t}\right)>V_{t}^{n d}\left(B_{t}, B_{t}^{D}, A_{t}\right)\right\}
$$

Note that the default set is two-dimensional, meaning that the distance between the value of repayment $V^{n d}$ and the value of default $V^{d}$ are affected not only by the level of government debt $B_{t}$, but also by the amount of public debt held domestically, $B_{t}^{D}$.

We find that the model with external and domestic debt preserves standard properties of quantitative models of sovereign default. Specifically, the model confirms a positive relationship between the total amount of outstanding debt with the probability of default, given a productivity state $A_{t}$ and domestic debt $B_{t+1}^{D}$.

Proposition 4. If default is optimal in state $\left(A_{t}, \bar{B}_{t}^{D}\right)$ for $B_{t}^{2} \geq\left|\bar{B}_{t}^{D}\right|$, default is also optimal for $B_{t}^{1}<B^{2} \geq\left|\bar{B}_{t}^{D}\right|$ given the same state $\left(A_{t}, \bar{B}_{t}^{D}\right)$, i.e. $\Gamma_{t}^{\delta}\left(B_{t}^{1}, B_{t}^{D}\right) \subseteq$ $\Gamma_{t}^{\delta}\left(B_{t}^{2}, B_{t}^{D}\right)$.

Proof. See Appendix A.

Further, we extend this finding by the observation that the default set $\Gamma_{t}^{\delta}$ is shrinking in the amount of debt held by the domestic banking sector.

Proposition 5. If default is optimal in state $\left(A_{t}, \bar{B}_{t}\right)$ for $B_{t}^{D, 2} \leq\left|\bar{B}_{t}\right|$, default is also optimal for $B_{t}^{D, 1}<B^{D, 2} \leq\left|\bar{B}_{t}\right|$ given the same state $\left(A_{t}, \bar{B}_{t}\right)$, i.e. $\Gamma_{t}^{\delta}\left(B_{t}, B_{t}^{D, 1}\right) \subseteq$ $\Gamma_{t}^{\delta}\left(B_{t}, B_{t}^{D, 2}\right)$.

Proof. See Appendix A.

The default probability is defined as the conditional cumulative probability density over the productivity state in period $t+1$ from the default set $\Gamma^{\delta}$ :

$$
\pi_{t}^{\delta}\left(B_{t+1}, B_{t+1}^{D}, A_{t}\right)=\int_{\Gamma^{\delta}\left(B_{t+1}, B_{t+1}^{D}\right)} f\left(A_{t+1}, A_{t}\right) d A_{t+1}
$$




\subsection{International investors}

International investors are risk neutral. The expected returns on the one-period discount bond are denoted by $E_{t}\left(1-\delta_{t+1}\right)$, which are discounted by an exogenously given risk-free investment opportunity with constant return $r^{f}$. Government bonds are priced according to the no-arbitrage condition

$$
q_{t}\left(B_{t+1}, B_{t+1}^{D}, A_{t}\right)=\frac{1-\pi_{t}^{\delta}\left(B_{t+1}, B_{t+1}^{D}, A_{t}\right)}{1+r^{f}} .
$$

From the price of the one-period discount bond we extract the period $t$ rate of return on public debt as $r_{t}^{g} \equiv q_{t}^{-1}-1$.

The effect of domestic government debt on the bond price follows jointly from Proposition 5, the definition of the default probability and the asset pricing equation of international investors (32):

Proposition 6. (i) Higher shares of total outstanding government debt purchased by the domestic banking sector on the secondary bond market lowers the probability of a sovereign default in period $t+1$, or formally $\pi_{t}^{\delta}\left(\bar{B}_{t+1}, B_{t+1}^{D, 2}, A_{t}\right) \leq \pi_{t}^{\delta}\left(\bar{B}_{t+1}, B_{t+1}^{D, 1}, A_{t}\right)$ for $0<B_{t+1}^{D, 1}<B_{t+1}^{D, 2} \leq\left|\bar{B}_{t+1}\right|$. (ii) A higher share of total outstanding government debt held by domestic banks lowers the spread on government bonds, i.e. $q_{t}\left(\bar{B}_{t+1}, B_{t+1}^{D, 2}, A_{t}\right)$ $\geq q_{t}\left(\bar{B}_{t+1}, B_{t+1}^{D, 1}, A_{t}\right)$.

Proof. See Appendix A.

\subsection{Equilibrium}

We examine a Markov perfect equilibrium where the state vector $s \in\left(B_{t}, B_{t}^{D}, A_{t}\right)$ is sufficient to define the optimal policy by all agents in the model.

Definition. The model's recursive equilibrium is given by

1. Value functions $\mathcal{V}, V^{n d}$, and $V^{d}$ for the government;

2. Policy functions of the government's default decision $\delta_{t} \in\{0,1\}$, and future borrowing $B_{t+1}$;

3. Policy functions for the private sector decisions on $C_{t}, L_{t}, M_{t}, \kappa_{t}, R_{t}^{\tau}$;

4. Bank policy function $\mathcal{F}$ for the inter-temporal decision on collateral purchases and dividend payments $B_{t+1}^{D, \tau}, D_{t}^{\tau}$;

5. A bond pricing equation from international investors for $q_{t}$;

such that given the government policies and the bond pricing equation, the household policies for consumption and labour solve the household's problem; given productivity and credit supply, the policies for labour and credit solve the profit maximizing problem of non-financial firms; given the bond pricing equation and credit demand, the banking sector decisions maximize financial sector dividends and satisfy the market clearing condition on secondary bond markets; the consumption plan $C_{t}\left(B_{t}, B_{t}^{D}, A_{t}\right)$ satisfies the resource constraint of the economy; the transfer policy $T_{t}\left(B_{t}, B_{t}^{D}, A_{t}\right)$ satisfies the government budget constraint; given $\Gamma_{t}^{\delta}\left(B_{t}, B_{t}^{D}\right)$ and $\pi_{t}^{\delta}\left(B_{t+1}, B_{t+1}^{D}, A_{t}\right)$, the 
bond pricing function $q_{t}\left(B_{t+1}, B_{t+1}^{D}, A_{t}\right)$ satisfies the no-arbitrage condition of foreign lenders.

\section{Analysis of the bank-sovereign link}

\subsection{Calibration and solution method}

We use Spanish data at a quarterly frequency over the period 2000q1 to 2011q4 in order to calibrate the model for the quantitative analysis. Although Spain did not default on its securities during the European sovereign debt crisis, it was among the group of countries that exhibited strong increases in country default risk that spilled over to the domestic banking sector (Section 2). Therefore, we think that the case of Spain provides a valuable testing ground to evaluate our model's propagation mechanism. We focus on the time period of membership within the European Monetary Union (EMU) until the end of 2011 when the ECB took non-standard policy measures at an unprecedented scale to stimulate the money market in order to alleviate the segmentation of funding conditions along national borders within the EMU. ${ }^{24}$ Limiting the analysis to this time period seems appropriate given that interventions from the central bank are absent in our model environment.

For the calibration of the household utility function, we use preferences proposed by Greenwood et al. (1988),

$$
U_{t}\left(C_{t}, 1-L_{t}\right)=\frac{\left(C_{t}-\frac{1}{\omega} L_{t}^{\omega}\right)^{1-\gamma}-1}{1-\gamma},
$$

and we take common values from the literature to calibrate the degree of risk aversion $\gamma=2$, and the wage elasticity of labour supply $\omega=1.455$. For the production function, we set the capital share of output to $\alpha=0.36$ which is a standard value for models calibrated to the euro area (Smets \& Wouters 2002). The risk-free rate $r^{f}$ is set to 1.0 percent at a quarterly frequency. This value is widely used in the literature and roughly in line with the average yield of German government bonds at a maturity of 10 years. Banks' discount factor is set to $\beta^{b}=1 /\left(1+r^{f}\right)$ such that the difference in valuation of government bonds between foreign investors and domestic banks is due to liquidity services only. The probability of re-entry to international capital markets after default is set to $\theta=0.083$, which is taken from Richmond \& Dias (2009), who find an average historical exclusion spell of three years for a cross-section of default episodes since 1980 in emerging market economies.

We take the parameters related to the process of aggregate productivity directly from Mendoza \& Yue (2012), setting $\rho=0.95$ and $\sigma_{\varepsilon}=1.7$ percent. We interpret the model predictions for aggregate volatility with caution, as the volatility properties of our model are influenced by the solution method as shown by Hatchondo et al. (2010). Therefore, we do not target the standard deviation and autocorrelation of the cyclical

\footnotetext{
${ }^{24}$ Primarily, the ECB launched two long-term refinancing operations with a maturity of three years which took a volume of about 1000 billion euros). See the corresponding ECB announcement from December $8^{\text {th }}$ 2011, http://www.ecb.europa.eu/press/pr/date/2011/html/pr111208_1.en.html
} 
Table 2: Baseline calibration

\begin{tabular}{lclll}
\hline & Parameter & Value & Source/Target & Data $^{(a)}$ \\
\hline Capital share of output & $\alpha$ & 0.36 & Literature & - \\
Risk aversion & $\gamma$ & 2 & Literature & - \\
Wage elasticity of labor supply & $\omega$ & 1.455 & Literature & - \\
Riskfree rate & $r^{f}$ & 0.01 & Literature & - \\
Bank's discount factor & $\beta^{b}$ & 0.99 & $1 /\left(1+r^{f}\right)$ & - \\
Probability of reentry & $\theta$ & 0.083 & Richmond \& Dias $(2009)$ \\
Persistence of TFP shock & $\rho$ & 0.95 & Mendoza \& Yue $(2012)$ \\
Std.dev. of TFP shock & $\sigma_{\varepsilon}$ & 0.017 & Mendoza \& Yue $(2012)$ \\
Rate on central bank reserves & $r^{R}$ & 0.0077 & $r^{f}-r^{R}$ & $23 \mathrm{bps}$ \\
Cost function collateral & $\psi$ & 0.245 & OLS estimate & \\
\hline Simulated Method of Moments & & & & \\
\hline Household's discount factor & $\beta$ & 0.92 & Default frequency & $0.65 \%$ \\
Capital stock & $K$ & 11.92 & $K / Y$ & 3.47 \\
Working capital requirement & $\eta$ & 1.074 & $\kappa / Y$ & 0.68 \\
Liquid liabilities & $N$ & 2.97 & $r^{\kappa}-r^{f}$ & $50 \mathrm{bps}$ \\
Efficiency parameter $\mathcal{P}$ & $\phi$ & 7.52 & $R^{e} /\left(\kappa+M+q B^{D}\right)$ & 0.0153 \\
Probability for lending bank & $\pi^{p}$ & 0.568 & $M / L^{\text {banks }}$ & 0.20 \\
Collateral requirement & $\chi$ & 0.257 & $B^{D} / B$ & 0.55 \\
\hline
\end{tabular}

Notes: ${ }^{(a)}$ Details regarding data sources and available sample periods are provided in the Appendix.

component of logged GDP, as it is common in the literature, but favour instead a closer comparability with the existing literature on endogenous output penalties.

The central bank deposit rate is calibrated by taking the average difference of the ECB rate on the deposit facility and the EONIA-swap rate. This yields a rate on central bank reserves that lies, on average, 23 basis points below the risk-free rate, which yields a value for $r^{R}$ of 0.77 percent.

The relationship of collateral quality to the interest rate on interbank markets is governed by the risk premium $\Psi\left(q_{t}\right)$. We assume a linear relationship and set the functional form to

$$
\Psi\left(q_{t}\right)=\psi\left(r_{t}^{g}-r^{f}\right)
$$

where the term in parentheses is the spread of the government bond yield over the risk-free rate, $\hat{r}_{t}^{g} \equiv r_{t}^{g}-r^{f}$. To calibrate $\psi$, we estimate the sensitivity of the interbank rate $r^{M}$ towards sovereign default risk from the data, using equation (21) and data at daily frequency over the period 31 March to 7 December 2011. The relatively short sample period is due to data availability. For the spread on the secured interbank market rate, we take the general collateral (GC) repo rate of Spain and subtract the 3-month EONIA-swap rate to obtain the interbank premium of Spanish collateral over the risk-free rate. The government risk premium is taken from the spread of a 10-year Spanish government benchmark bond over the German Bund. OLS regressions yield an average marginal effect of $\psi=0.245$.

The remaining parameter values $\left\{\beta, K, \eta, N, \pi^{p}, \chi, \phi\right\}$ are found using the simulated 
method of moments (SMM) with the following calibration targets in the stochastic stationary state. The historical default frequency of Spain is 0.65 percent according to data from Sturzenegger \& Zettelmeyer (2007) covering the period 1820 to $2011 .^{25}$ The capital-to-output ratio from the European Commissions' Ameco database takes the value of 3.47 over the period of interest ranging from 2000 to 2011. The working capital need at a quarterly frequency is approximated using data from the Bank of Spain on the nominal volume of short-term bank loans to the non-financial sector with a maturity of up to one year over nominal GDP, which yields a target for $\kappa / Y$ of 68 percent. Further, using the bank lending rate on credit to non-financial corporations with a maturity below one year, we find an average credit premium of 50 basis points at a quarterly frequency over the EONIA-swap rate.

The parameters $\phi, \pi^{p}$, and $\chi$ are chosen to target long-run relationships in the financial sector. In order to approximate the liquidity preference of banks, we use the bank liquid reserves to bank asset ratio from the World Bank. According to the data, it takes an average value of 1.53 percent over the period 2000 to 2011 and we target the long run average of the ratio $R^{e} /\left(\kappa+M+q B^{D}\right)$ from the model to match this statistic.

A central value in our calibration is the ratio of wholesale funding to aggregate bank liabilities in the stochastic steady state $\left(M / L^{\text {banks }}\right)$, where we derive aggregate bank liabilities in the model from bank balance sheets as $L^{\text {banks }}=N+M+q B^{D} \cdot{ }^{26}$ The ratio $M / L^{\text {banks }}$ has implications for the size of the default penalty through the freeze on the interbank market. In the baseline calibration, we approximate the aggregate use of wholesale funding in the Spanish banking sector by taking the ratio of deposits by domestic credit institutions over total domestic liabilities available from the Bank of Spain at a monthly frequency. Taking the long-run average of this ratio, we set the calibration target to $M / L^{\text {banks }}=0.20$. We consider this to be a conservative assumption on the dependence of Spanish banks on wholesale funding given that we do abstract from cross-border flows within the euro area. ${ }^{27}$ Finally, regarding the ratio of domestic to total government debt we set the target to roughly 55 percent using the sovereign investor base estimates by Arslanalp \& Tsuda (2012) starting in the first quarter of 2004.

From the SMM, we obtain a relatively low value for the household discount factor, $\beta=0.92$, which is common in the literature on endogenous sovereign default. ${ }^{28}$ The value obtained for the working capital requirement $\eta=1.074$ is not directly comparable to the literature on emerging market business cycles ${ }^{29}$ or to Mendoza \& Yue (2012), since working capital in our model is financed by domestic banks while the literature on emerging market business cycles refers to a borrowing requirement on

\footnotetext{
${ }^{25}$ Spain defaulted four times in the $19^{\text {th }}$ century and exhibits a historical default frequency that is very close to that of Argentina.

${ }^{26}$ From an accounting perspective, government bonds constitutes bank equity according to the balance sheet equation $R^{p}+\kappa+q B^{D, p}=N^{p}+M+K^{b, p}$, where type $p$ bank equity $K^{b, p} \equiv q B^{D, p}$ is the residual to equate the asset with the liability side.

${ }^{27}$ For a comparison, Giannone et al. (2012) estimate that wholesale funding makes up to 60 percent of banking sector liabilities in the euro area.

${ }^{28}$ E.g. Mendoza \& Yue (2012) use $\beta=0.88$.

${ }^{29}$ Neumeyer \& Perri (2005) and Uribe \& Yue (2006) use values in the range of 1 to 1.2 in order to generate an effect of a stochastic interest rate on output.
} 
international capital markets. This modelling difference by itself justifies a higher parameter value for $\eta$, in particular given that external finance in Europe is traditionally bank-dominated. ${ }^{30}$ For the remaining parameters, we find $K=11.92, N=2.97$, $\pi^{p}=0.568, \chi=0.257$, and $\phi=7.52$.

In order to find a numerical solution to the equilibrium described in Section 3.9, we follow the literature on quantitative models of sovereign default using value function iteration on the government problem on a discrete state space. The exogenous productivity state variable is defined on a grid with 15 nodes. We use Tauchen's (1986) procedure to discretise the state space of total factor productivity according to its law of motion from equation (6). The endogenous state variables are discretised over a grid with equidistant nodes, and intervals $B \in\left[B_{\min }, 0\right]$ and $B^{D} \in\left[0, B_{\max }^{D}\right]$, where $B_{\max }^{D}=-B_{\min }$. We make sure that the boundary of total government debt is nonbinding along the simulated equilibrium path. Detailed explanations regarding the computational strategy are laid out in Appendix D.

\subsection{Sovereign risk and financial frictions}

The financial frictions in the model propagate endogenous sovereign default risk to financial market conditions, which in turn determine real sector allocations. In this section, we spell out the contributions of the main assumptions regarding these ex ante costs of sovereign risk in a numerical example before proceeding to the quantitative evaluation of the dynamic properties of the set-up. Specifically, we show partial equilibria as laid out in Section 3.6 for different calibrations of reduced form financial frictions.

Figure 4: Interaction of default risk and financial frictions
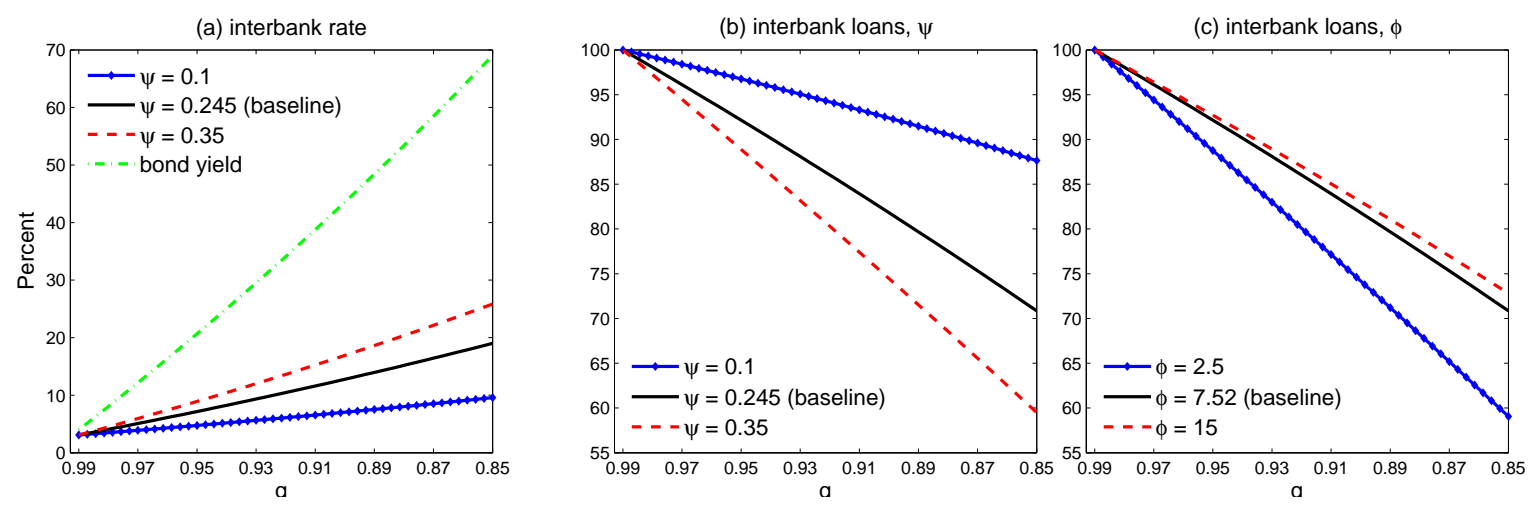

Note: Productivity fixed at $e^{A_{t}}=1$, and a non-binding collateral constraint. Interest rates in Panel (a) in percentage points at annual frequency.

Figure 4 illustrates the interaction of financial frictions and sovereign risk in the repayment equilibrium. Default risk is shown in terms of a decreasing bond price

\footnotetext{
${ }^{30}$ Using the approximation of working capital needs following Schmitt-Grohé \& Uribe (2007), i.e. two thirds of the Spanish contribution to euro area M1 over Spanish GDP, yields a similarly high parameter value for $\eta$, which is in line with higher observed working capital needs in the euro area compared to the U.S. (Christiano et al. 2010).
} 
according to investors' pricing equation (27). The parameter $\psi>0$ governs the cost of wholesale bank funding according to the risk premium on secured interbank debt $\Psi\left(q_{t}\right)$. The lower the value of $\psi$, the lower is the elasticity of the interbank rate on sovereign risk (Fig. 4a). The increase in the interbank rate propagates into lower interbank loan volumes through the interaction with the need for liquid reserves on interbank loans (Fig. 4b).

How does the precautionary motive for liquidity accumulation influence the decline in intermediated funds? This friction introduces a spread over the interbank rate $r_{t}^{M}$ in its relationship to the credit rate $r_{t}^{\kappa}$. The optimality condition on interbank loans from equation (19) illustrates this point. Assume that the collateral constraint is non-binding, we can approximate equation (19) by the expression:

$$
r_{t}^{\kappa}=\frac{r_{t}^{M}-\frac{r^{R}}{\phi}}{1-\frac{1}{\phi}}
$$

An exogenous increase in sovereign risk results in a rise in $r_{t}^{M}$ according to the risk premium $\Psi\left(q_{t}\right)$, which in turn leads to an even stronger increase in the credit rate in order for the relationship to hold. ${ }^{31}$ The intuition follows from the opportunity cost of liquidity buffers that increase with higher funding costs on the interbank market.

Figure 4(c) shows variations in the parameter $\phi$ from its baseline value. With an increase in $\phi$, the interbank loans react less sensitive to an increase in default risk, as the need to build liquidity buffers for precautionary motives is reduced. This renders interbank borrowing more attractive, since a higher fraction of interbank loans can be channelled to profitable credit.

Figure 5: Effect of occasionally binding constraint on allocations

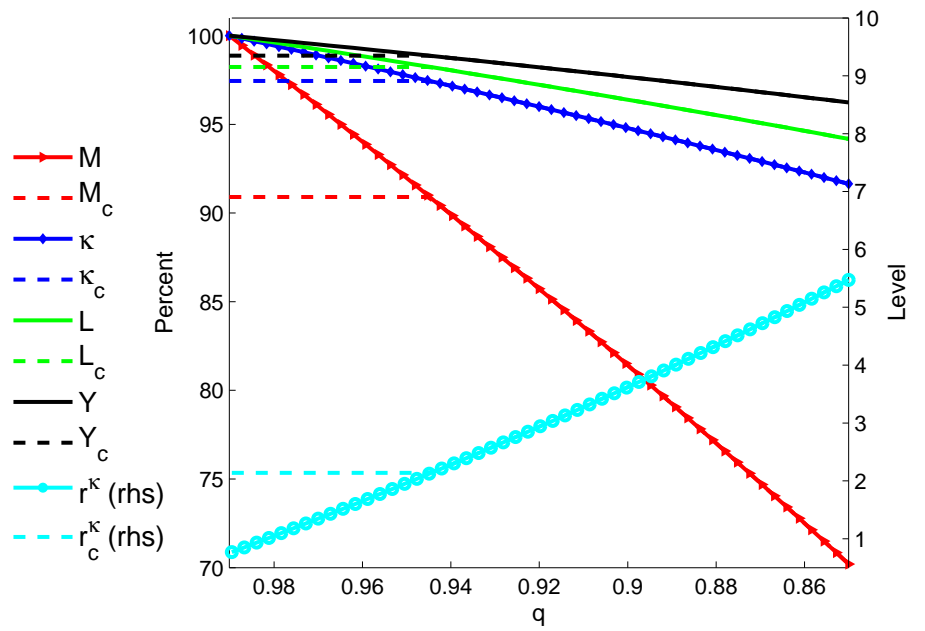

Note: Allocations in unconstrained and constrained (dotted lines) equilibrium. Credit rate in levels at annual frequency (rhs).

Next, we investigate the effects of an occasionally binding collateral constraint on

\footnotetext{
${ }^{31}$ This follows from $1 /[1-(1 / \phi)]>1$. Further, note that $\psi>1$ is a necessary condition for an equilibrium on the interbank market.
} 
the equilibrium allocations. In Figure 5, the allocations with a non-binding constraint are compared to those under a binding constraint, both under the baseline calibration. Interbank loans, credit, labour and output are shown in percentages compared to the case of a least restricted economy, that is, given a non-binding collateral constraint and absent the risk of sovereign default. The amount of collateral is exogenously chosen in this example to induce a drop in interbank loan volume of 10 percent absent sovereign risk.

While the decline in interbank intermediation with rising sovereign risk is known from the previous explanations, the shortage of collateral assets imposes, on top of that, a borrowing constraint on the interbank market. In the constrained equilibrium, the amount of credit available to the non-financial sector is thus limited from the supply side. Through the working capital requirement, this has an immediate impact on labour input, which needs to be financed with credit from banks. With cash demand of non-financial firms remaining unmet, firms need to cut back on labour input for production. At some degree of default risk, the effect on interbank loans from financial frictions is stronger than the original scarcity of collateral assets, such that the collateral requirement is not binding any longer.

\subsection{Default, credit crunch, and domestic debt}

In this section, we characterise the optimal default decision in general equilibrium. We show that the default decision is affected by the size of the disciplining penalty and by domestic holdings of debt. Collateral purchases depend on the productivity state and propagate aggregate shocks over time.

The penalty from defaulting on sovereign debt results from a breakdown of interbank intermediation when the market value of government bonds collapses to zero. Thus, financial resources can no longer be channelled to their most effective use and type $p$ banks are limited in their funds to the existing stock of liquid assets when extending credit to non-financial firms. The associated output cost of sovereign default is a consequence of the resulting credit crunch in the default period that shrinks the feasible set of allocations for the production sector of the model economy. The working capital assumption imposes an upper bound to the amount of labour which can be employed in the economy under autarky. From equation (4) we get the equilibrium condition $L_{t}=\kappa_{t} /\left(\eta W_{t}\right)$. Hence, as $\kappa_{t}$ drops from the supply side, output falls as wage bills cannot be financed. However, the output cost of a sovereign default induced credit crunch are not independent of the stance of the business cycle.

Figure 6a shows the difference between allocations in the repayment equilibrium in comparison to the default equilibrium as a function of total factor productivity. For the repayment equilibrium, we assume that there is no default risk. In the unconstrained repayment equilibrium, a credit crunch associated with a sovereign default is more than six times higher in a high productivity state compared to a low productivity state. The reason is that credit demand is larger during a boom, leading to more interbank trading. With elevated labour productivity, non-financial firms are willing to pay higher wages which actuates labour supply. Hence, credit demand varies quite strongly over the cycle. The interbank freeze induced by a sovereign default shrinks 
Figure 6: Cost of default and domestic debt accumulation

(a) Cost of sovereign default over the cycle

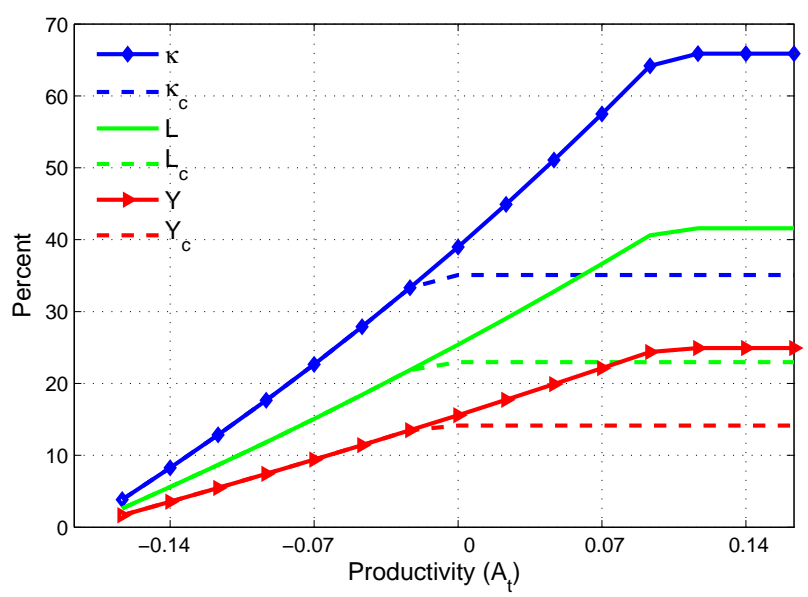

(b) Secondary bond market pricing

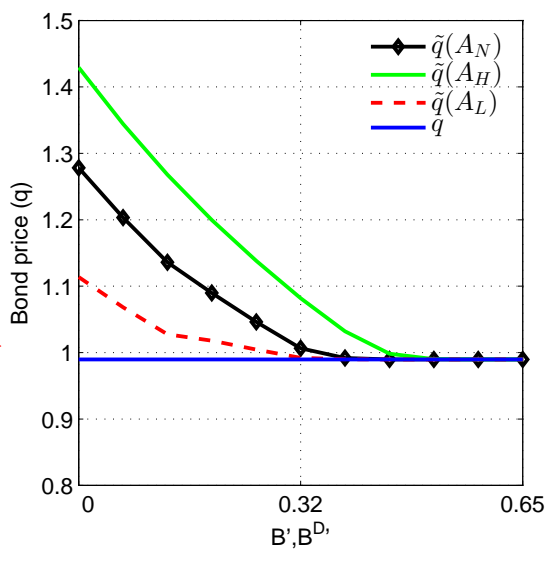

Note: Panel (a). Percentage reductions in the default regime compared to the repayment regime absent sovereign default risk. Dotted lines illustrate the scenario with a binding collateral constraint in the repayment equilibrium. Panel (b) - $A_{N}$ denotes a neutral productivity realisation $\exp \left(A_{t}\right)=1$, and $A_{L}<A_{N}<A_{H}$.

available credit by up to 60 percent. This supply-side reduction of credit causes output to drop by more than 20 percent of GDP in high productivity states. At the same time, low demand for credit make a credit crunch less painful in terms of output losses during deep recessions, when the costs of default in terms of output losses are below 10 percent.

The occasionally binding collateral constraint introduces asymmetry in the form of downward skewness into the business cycle, as can be seen from the constrained allocations in Figure 6a. Since collateral holding is an endogenous state variable that is determined on the basis of expected future productivity realisations, unexpected large productivity realisations might not necessarily lead to a boom, as credit and output remain constrained through the interbank market. Domestically held government debt is, thus, not only shaping default incentives in the dynamic model, but also an important determinant of business cycle fluctuations.

Furthermore, the credit crunch is relatively less costly in the constrained regime when financial intermediation is limited by domestic holding of government debt. As a consequence, default incentives are directly affected by financial market allocations. This illustrates that causality is running in both direction in the model, from sovereign risk to the banking sector, but also from a dysfunctional interbank market to default risk. It is worth noting that this reverse causality is not the result of an explicit or implicit banking sector bailout guarantee from the public sector. ${ }^{32}$

Figure $6 \mathrm{~b}$ presents the pricing of collateral assets by banks in comparison to the pricing of government debt by international investors on the bond market. Pricing

\footnotetext{
${ }^{32}$ Acharya et al. (2014) model the link between public bailout policies and sovereign credit risk.
} 
vectors $\tilde{q}$ are the optimal policy functions extracted from the solved model for different states of productivity, $A_{t}$. Specifically, we take the price vectors at three levels of productivity. To begin with, we take a neutral productivity state $\tilde{q}\left(A_{N}\right)$, with $\exp \left(A_{N}\right)=1$. In line with the stylized representation of the secondary bond market in Figure 3, demand for government bonds from domestic banks is downward sloping, since the liquidity premium on government debt is falling with increasing collateral positions. The equilibrium quantity of bank purchases of government debt are determined where the no-arbitrage condition $\tilde{q}=q$ is satisfied. Next, we are interested to see how current productivity realisations change incentives for domestic debt accumulation. Considering a higher (lower) productivity state today shifts demand for collateral upward (downward). This is in line with expected credit demand in the following period which is based on expected productivity, $E_{t}\left(A_{t+1}\right)=\rho A_{t}$. Given higher expected profitability of intermediation, banks have an incentive to accumulate domestic debt in a pro-cyclical manner, as the liquidity premium $\hat{\lambda}_{t}$ from Proposition 2 is also pro-cyclical. In general equilibrium, this has implications for the cyclicality of sovereign risk premiums, as from Proposition 6 domestically held debt is by itself lowering the incentive to opt for debt repudiation, contributing to overall pro-cyclicality of the financial sector.

Figure 7: Decision to default in the state space

(a) Along the TFP dimension

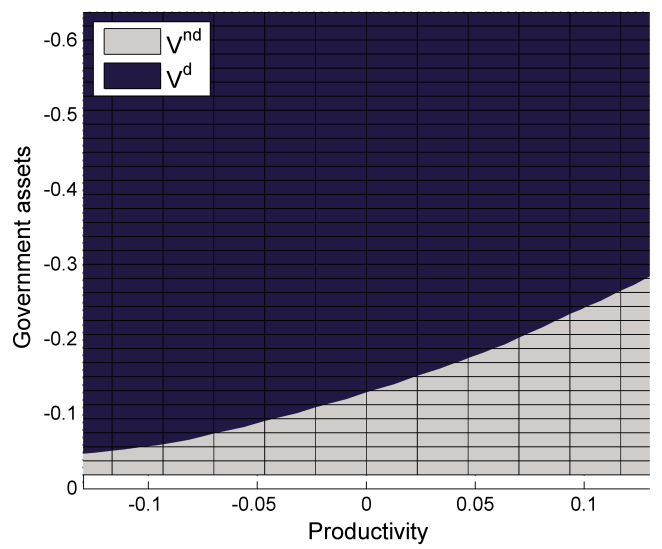

(b) Along the dimension of domestic debt

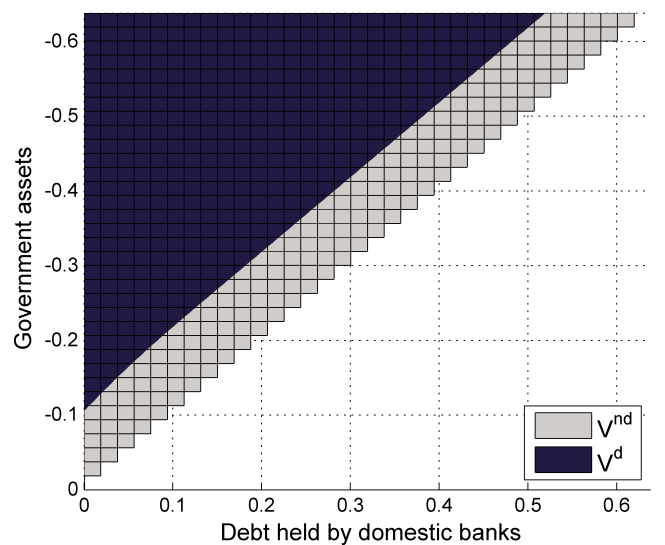

Note: Dark shaded region represents states of optimal default, while the area in light grey represents repayment. Government assets in percent over steady state output. In Panel (a), debt held by domestic banks is held constant at a sufficiently high level such that the collateral constraint is non-binding. In Panel (b), total factor productivity is constant at its mean value.

The model exposes two channels that contribute to the counter-cyclical behaviour of the government bond risk premium, namely the pro-cyclical output cost of sovereign default and domestic debt accumulation in the decentralised equilibrium. Figure 7 shows the combined effect of the two channels on the enforceability of total government debt. Technically, this shows the value functions under default $V^{d}$ and repayment $V^{n d}$. The light grey shaded area represents the region where the value of repayment 
Figure 8: Bond prices and default set

(a) Bond price schedule

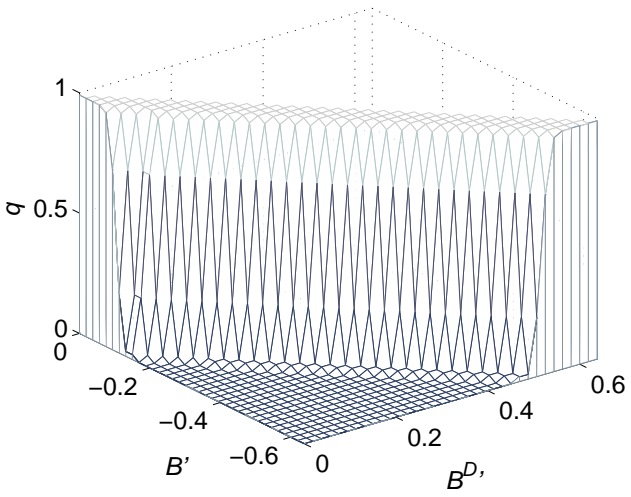

(b) Default set $\Gamma^{\delta}\left(B, B^{D}\right)$

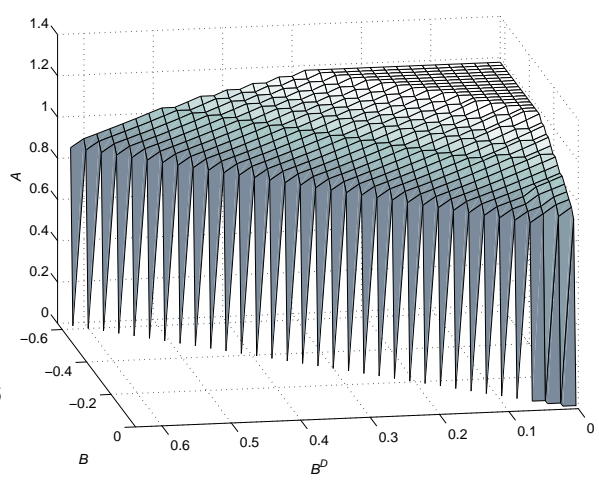

Note: Panel (a). The bond price schedule $q_{t}$ is conditional on current state $s \in$ $\left(B_{t}, B_{t}^{D}, A_{t}\right)$ and represents the set of financial contracts available between foreign investors and the government, for different period $t$ choices $\epsilon_{t} \in\left(B_{t+1}, B_{t+1}^{D}\right)$. Asset positions are in percent of steady state output. Panel (b). Plotted is the frontier of the default set $\Gamma\left(B, B^{D}\right)$, or $\min \left(A_{t}\right) \in s: V_{t}^{d}\left(B_{t}, B_{t}^{D}, A_{t}\right)>V_{t}^{n d}\left(B_{t}, B_{t}^{D}, A_{t}\right)$.

dominates the value of default in the government problem, whereas in the dark shaded area the government decides to default.

In a framework with non-Ricardian output effects of government debt, we find that transitory productivity shocks have a strong effect on the borrowing limit that is more than five times as large in high productivity states compared to very low productivity states (Figure 7a). This result is contrary to the findings of Aguiar \& Gopinath (2006) who show that transitory productivity shocks in an endowment economy cannot generate a significant steepness of the indifference line which separates the default region from the repayment region. The sensitivity of the debt ceiling to aggregate shocks translates into a quantitatively important region of risky borrowing, which is defined over the interval of government indebtedness where foreign investors charge a risk premium over the risk-free rate (Figure 8a).

Further, it is the net foreign asset position that determines default incentives in the presented setting (Figure $7 \mathrm{~b}$ ). The reason is that domestic government debt does not directly affect the aggregate resource constraint of the economy, as it is consolidated over dividend payments with the budget constraint of the representative household. ${ }^{33}$ By contrast, benefits from defaulting are due to foreign owned government debt as debt repayment leads to wealth transfers abroad. In the extreme, government debt is always enforced if total outstanding debt is held domestically. ${ }^{34}$

This finding is in line with qualitative models on sovereign default with external and domestic debt. Guembel \& Sussman (2009) develop a political economy model where

\footnotetext{
${ }^{33}$ Notwithstanding, domestic debt does affect the resource constraint indirectly through aggregate production.

${ }^{34}$ The 45 -degree line in Figure $7 \mathrm{~b}$ indicates the set of states where $-B_{t}=B_{t}^{D}$. Our result rests on the assumption that taxation is non distortionary.
} 
the household sector is heterogeneous in its holdings of government assets. They show that an electoral system with majority voting leads to a conflict of interest which is able to enforce foreign-owned sovereign debt even if penalties are absent. For this mechanism to work, the inability to discriminate among bond holders is a crucial assumption. Similarly, Broner et al. (2010) show that the possibility of secondary market trading alone gives rise to full enforcement of sovereign debt contracts if domestic bond holders are unable to collude.

We introduce secondary bond market trading under the assumptions that (i) the government cannot discriminate and that (ii) the aggregate amount of domestically held debt is public information. This allows banks to form expectations on default probabilities in period $t+1$ by taking account of their own decision to accumulate domestic debt. Domestic debt thereby constitutes a coordination device for the government, domestic and foreign investors alike. However, this device itself is closely linked to the business cycle, making it weaker during recessions when domestic banks have lower incentives to hold government debt. Differently said, although there exists a repayment equilibrium for very high levels of government debt, the economy cannot coordinate to this point along the equilibrium path as banks do not have the incentive to accumulate a high enough share of outstanding government debt. ${ }^{35}$

Finally, there is propagation of the productivity shock over time. Since the productivity process is persistent, the domestic banking sector will raise its demand for collateral as it expects an increased demand for credit and intermediation in case of an above average productivity realisation. An improved net foreign asset position reduces the interest rate on government debt (Proposition 3). This has a positive feedback effect over time, since a higher share of domestic debt lowers default incentives in the consecutive period (Proposition 6). At lower levels of sovereign risk, aggregate output is higher since the cost of finance to non-financial firms is not inflated by financial frictions. Thus, the repayment equilibrium turns out to be self-enforcing.

However, the same mechanism induces a downward spiral in response to adverse shocks. After a series of bad shocks to productivity, domestic banks reduce their investment in collateral and pay out dividends to households. Credit demand drops, which lowers the penalty from a credit crunch. Under these conditions, the burden from repaying international investors is high, rendering default an attractive option from the planner's perspective in bad states of the world. ${ }^{36}$ Figure $8 \mathrm{~b}$ visualises the set of states $s \in\left\{A_{t}, B_{t}, B_{t}^{D}\right\}$ for which default from an ex post perspective turns out to be the optimal policy of the benevolent government.

\footnotetext{
${ }^{35}$ Thereby, the model does not support the crowding out hypothesis in the course of the European sovereign debt crisis as formulated in Broner et al. (2014). This is due to the fact that secondary market trading does not include arbitrage trading as in Broner et al. (2010). Besides, government debt and credit do not enter the same flow of funds constraint in this model as they have different maturities.

${ }^{36}$ While the theoretical literature stresses the possibility of partial insurance against very bad shocks through default (Zame 1993), the empirical literature finds a weaker relationship (Tomz \& Wright 2007).
} 


\section{Quantitative results}

\subsection{Stochastic stationary state and cyclical behaviour}

We simulate the model in order to extract the stochastic stationary state and cyclical co-movement generated by the bank-sovereign link in our framework. To this end, we simulate the stochastic process for aggregate productivity 3000 times for 864 periods in each simulation round. We feed the generated series into the model and delete the first 100 elements such that we are left with 191 years of observations, which captures the 1820-2011 time span used to calibrate the default frequency. Data from 48 periods prior to a sovereign default generated by the model is extracted to calculate the moment statistics that cover the 2000q1 to 2011q4 era. The underlying assumption is that Spain most likely would have lost capital market access and defaulted as a consequence in the course of 2012 if non-standard measures taken by the ECB to calm secondary markets would not have been taken. ${ }^{37}$ We evaluate the model given moments from available Spanish data, as described in the baseline calibration. Additionally, data for output and consumption is taken from the OECD's Quarterly National Accounts. We use the GDP deflator in order to transform nominal loan volumes into real volumes and we extract the cyclical component of logged variables using the hp-filter with the standard smoothing parameter for quarterly data.

Table 3 column (2) summarises the results under the baseline calibration. The model is able to generate a comparatively high debt-to-GDP ratio with an average of 21.4 percent. Although this is still below the debt level observed in the data, models with ad hoc default penalties on output endowment realisations have typically difficulties to generate such high public debt levels. The asymmetric default penalty from the interbank freeze contributes to our result, similar to the findings of Mendoza \& Yue (2012). The planner faces two separate incentives to borrow when deciding on the optimal debt policy. First, there is the marginal benefit of borrowing from capital markets based on the consumption smoothing preferences in the light of risk-averse and impatient households, which is common to existing models of sovereign default. A novel borrowing incentive arises due to the liquidity services that are required to facilitate the creation of credit, which is used for production in the economy. Thereby arises simultaneously the incentive to borrow large amounts from capital markets in order to accommodate underlying financial frictions, while at the same time being disciplined by the endogenous penalty mechanism to adjust the debt level over the business cycle such that default is prevented. As a result, the amount of outstanding government debt is more sensitive to transitory productivity shocks and high debt levels are sustained in the stochastic stationary state. While high debt-to-GDP ratios can also be generated at low default frequencies (Aguiar \& Gopinath 2006), our model yields a realistic default frequency of 0.63 percent.

We find a close link between the average default frequency and the sovereign risk premium, which is a common finding in the literature given the direct link of the default

\footnotetext{
${ }^{37}$ This does not seem to be a very unrealistic assumption given that Spain and Italy suffered further increases in government bond yields in the first half of 2012. It was the ECB's announcement of unlimited interventions in secondary sovereign bond markets under the OMT programme in August 2012 that prevented a further escalation of the debt crisis in the euro area.
} 
Table 3: Baseline results and robustness

\begin{tabular}{|c|c|c|c|c|c|}
\hline & $\begin{array}{c}(1) \\
\text { Data }\end{array}$ & $\begin{array}{c}(2) \\
\text { Baseline }\end{array}$ & \multicolumn{3}{|c|}{ Robustness } \\
\hline & & & $\psi=0$ & $\phi=10^{3}$ & $\begin{array}{c}\psi=0 \\
\phi=10^{3}\end{array}$ \\
\hline \multicolumn{6}{|l|}{ Stochastic stationary state } \\
\hline Debt-to-GDP ratio & 39.1 & 21.4 & 21.6 & 20.1 & 20.1 \\
\hline Dom. debt share & 54.9 & 61.7 & 61.9 & 59.1 & 59.0 \\
\hline Sovereign premium & 0.122 & 0.754 & 0.734 & 0.747 & 0.738 \\
\hline Credit premium & 0.504 & 0.158 & 0.073 & 0.061 & -0.120 \\
\hline Repo premium & 0.194 & -0.045 & -0.230 & -0.047 & -0.230 \\
\hline Frequency of default & 0.65 & 0.63 & 0.624 & 0.626 & 0.626 \\
\hline Output drop at default & - & 19.6 & 19.9 & 19.8 & 20.0 \\
\hline \multicolumn{6}{|l|}{ Relative volatility } \\
\hline Std.consumption/Std.output & 1.10 & 1.06 & 1.06 & 1.06 & 1.06 \\
\hline \multicolumn{6}{|l|}{ Correlations } \\
\hline \multicolumn{6}{|l|}{ (A.) with output } \\
\hline Lending & 0.77 & 1.00 & 1.00 & 1.00 & 1.00 \\
\hline Sovereign premium & -0.14 & -0.44 & -0.42 & -0.43 & -0.41 \\
\hline Credit premium & -0.32 & -0.03 & 0.27 & -0.03 & 0.26 \\
\hline Repo premium & - & -0.44 & 0.0 & -0.43 & 0.0 \\
\hline \multicolumn{6}{|l|}{ (B.) with sovereign premium } \\
\hline Credit premium & 0.84 & 0.40 & -0.17 & 0.44 & -0.16 \\
\hline Lending & -0.26 & -0.46 & -0.41 & -0.44 & -0.40 \\
\hline
\end{tabular}

Notes: Details regarding the data are available in Appendix E.

probability with the bond pricing equation of international investors. In this context, the no-arbitrage condition of international investors from Proposition 3 prevents that the liquidity premium on bond prices from Proposition 2 translates overall into a lower risk premium on government debt. ${ }^{38}$ The sovereign risk premium generated under the baseline calibration takes a value of 0.754 percent on average, which is substantially higher than the observable average risk premium on Spanish government bonds over German Bund. As shown by Bernoth \& Erdogan (2012), the yield on Spanish debt over the period 2000-11 is affected by the convergence period after entering EMU when investors charged a historically low risk premium and is not necessarily a representative sample period.

The credit premium and the interbank premium as targeted in the SMM procedure are both functions of the parameters governing the spillover of sovereign risk to financial frictions. Note that the interbank market premium $\bar{r}^{M}-r^{f}$ is below zero in the stochastic stationary state of the model since the opportunity investment for unproductive banks is $r^{R}<r^{f}{ }^{39}$ With low default risk in the majority of states along the equilibrium path, we obtain $\bar{r}^{M}<r^{f}{ }^{40}$ Further, an average spread is also maintained

\footnotetext{
${ }^{38}$ Models that generate a higher risk premium compared to the default frequency use modifications of the utility function of the international investor, see Lizarazo (2013) and Pouzo \& Presno (2013).

${ }^{39}$ Variables with a bar denote steady state values.

${ }^{40}$ This is in line with the data, as the secured interbank rate EUREPO usually trades below the unsecured interbank rates EURIBOR and EONIA swap. Only the short time period of elevated sovereign risk available for the Spanish GC repo rate indicates a slightly positive spread.
} 
between the secured interbank rate $\bar{r}^{M}$ and the credit rate $\bar{r}^{\kappa}$ which is in our model due to the liquidity preference.

The data shows parallels in Spanish business cycle moments with stylised facts from emerging markets. Namely, the volatility in consumption exceeds that of output, and the sovereign risk premium is negatively correlated with the cycle. The model is able to reproduce both moments, although it overestimates the negative correlation of output with the sovereign risk premium. The counter-cyclical sovereign risk premium is a result of the endogenous default penalty which makes default more attractive during recessions, while there are virtually no defaults during boom periods. As a consequence, the counter-cyclical risk premium renders public borrowing less attractive during recessions, while simultaneously leading to a consumption boom during expansions given loose credit conditions on international capital markets and impatient households. On top of that, the planner is trading-off the expected future distortions on domestic financial markets when taking his optimal borrowing decision. In models with exogenous endowment processes, the trade-off on borrowing higher amounts takes only the interest rate effect into consideration.

In Mendoza \& Yue (2012), increases in the cost of borrowing for the public sector translate, by assumption, into a higher cost of credit for the private sector, which induces an inefficient substitution into domestic goods in the production of intermediate goods that weighs on output. ${ }^{41}$ In our framework, the propagation of higher sovereign risk into rising cost of private credit is explicitly modelled. The credit rate $r_{t}^{\kappa}$ depends primarily on aggregate productivity and the funding situation of domestic banks. As the funding conditions are tied to sovereign risk during times of fiscal stress, the collateral channel of sovereign risk is able to account for a positive correlation on public and private sector risk premiums. The model underestimates the correlation coefficient with 0.40 while the data exhibits a stronger correlation of 0.84 .

The same mechanism leads to an overall mildly counter-cyclical credit premium of -0.03. There are two off-setting effects in the model that shape the correlation of the credit premium with output. While the credit premium is demand-determined and pro-cyclical in normal times absent fiscal stress, it turns counter-cyclical in the model during crisis periods, as it is discussed in the next section.

The data shows a high correlation of lending to non-financial firms with output. This pro-cyclicality of credit is overestimated by the model, as working capital lending is perfectly correlated with output. With a fixed capital stock, output has only two sources of fluctuations, labour input and productivity, which are both highly correlated, too. As labour input requires working capital lending, credit is directly linked to production. With endogenous capital accumulation, this link may well be weaker.

Finally, Spanish data shows that the sovereign risk spread of government bonds over German Bunds is negatively correlated with short-term lending to non-financial firms. The model closely matches this negative correlation in the data and rationalises the result by providing a theory of endogenous sovereign risk and the supply of credit in general equilibrium.

\footnotetext{
${ }^{41}$ The authors rationalise this result by showing that a government diverts the outstanding private loans on international capital markets in the event of a default. This leads to coinciding risk of default in the public and the private sector.
} 
We conduct a range of robustness checks in order to validate our findings. In column (3), we eliminate the risk premium on secured interbank debt. This implies a repo premium of -23 basis points from the calibration since $r_{t}^{M}=r^{R}$, independent of sovereign risk. Since the bank funding conditions do not react to the level of default risk any longer, the credit premium turns strongly pro-cyclical as the demand effect dominates credit conditions over the business cycle. Also, the co-movement of interest rates can no longer be replicated by the model. This underlines that supply side effects of bank credit are important for the explanation of cross-correlations and long-run averages of different interest rates in the model. However, since the ex post penalty from defaulting remains in place, the stochastic steady state levels of government debt are not affected. The marginal increase of the debt-to-GDP ratio follows from the fact that there are less adverse consequences of sovereign risk, which allows the government to marginally increase its level of indebtedness.

In column (4), we eliminate the liquidity preference and set $\phi=10^{3}$. As a direct consequence, the credit premium in the steady state drops as the opportunity cost vanishes from accumulating liquid reserves when productive banks borrow from the interbank market since $R_{t}^{e} \rightarrow 0$. However, the remaining results stay qualitatively and quantitatively the same as under the baseline calibration.

Finally, we eliminate both frictions simultaneously in column (5). The results are similar as in column (3), suggesting that the risk premium is more important for the quantitative results than the liquidity preference.

\subsection{Debt crisis, collateral squeeze, and macroeconomic dy- namics}

Against the background of the stylised facts from the euro area sovereign debt crisis, we are interested in the qualitative and quantitative predictions of the model around default events. We present the average behaviour of time series produced by our model simulations in a default window including 4 years prior and after a default event (Figure 9).

The effect of the sovereign risk channel unfolding in the run-up to a sovereign debt crisis event are presented in Figure 9a. The risk premium on sovereign debt rises steadily from its long-term mean before a default takes place. In the pre-crisis period, lower than average productivity realisations dampen the demand for credit, which translates into a slightly lower credit premium on private debt. The initial decline in the credit rate is demand-driven, reflecting the below average labour productivity, which has to compensate for the cost of credit according to the optimal labour demand condition (5). With rising sovereign risk and a further deterioration in the quality of collateral, funding costs of banks start to increase. In response, lending banks charge higher credit rates on working capital loans to non-financial firms even though demand is falling. Additionally, the rise in the cost of interbank loans interacts with the preference for liquidity, that requires lending banks to build excess reserves on each unit of borrowed funds on the interbank market. This preserves a spread between the interbank rate and the credit rate, bearing an additional rise in the credit rate. As a result, the interest rates on public and private sector debt are highly correlated shortly 
Figure 9: Macrodynamics around default events

(a) Sovereign risk channel

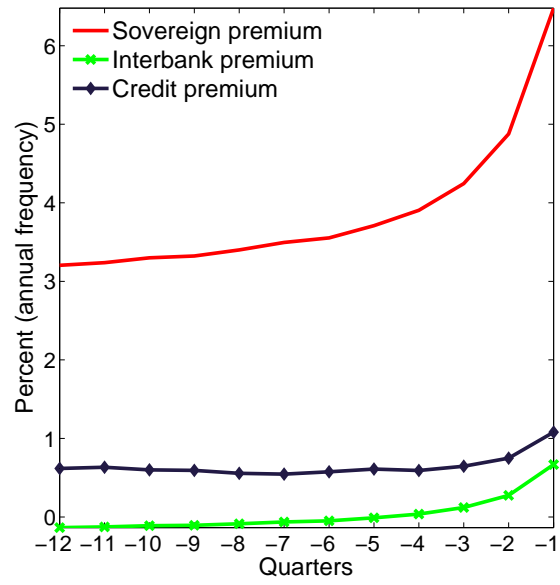

(b) Credit crunch

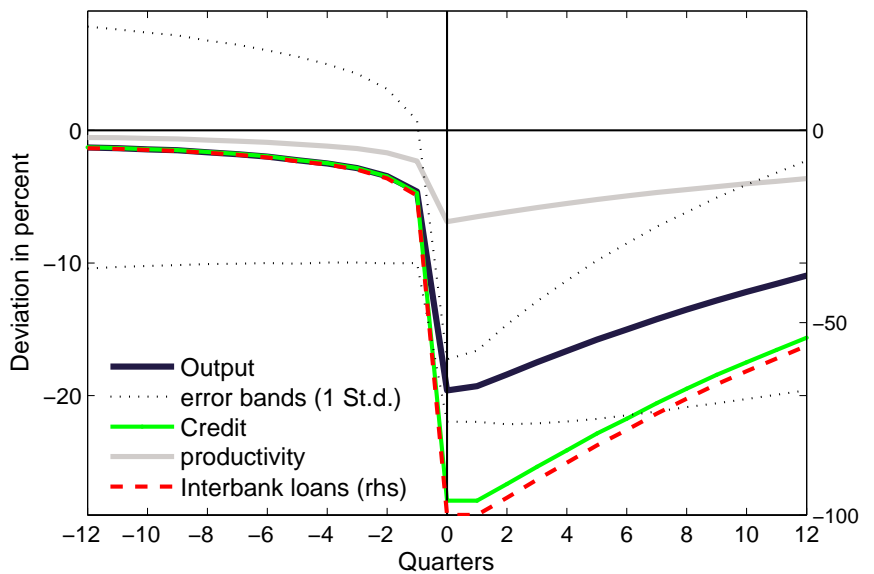

before a default takes place.

In comparison to the Argentinian default of 2001, the macroeconomic dynamics around default events as characterised by the bank-sovereign link are different in that our model predicts (i) a more severe recession related to a sovereign debt crisis; (ii) the impact effect of default on output to be much stronger; and (iii) that recessions last longer (Figure 9b).

Quantitative models of sovereign default typically predict a recession prior to default as debt repayment gets more painful during these times (Arellano 2008). ${ }^{42}$ However, the interaction of sovereign risk with financial frictions in the presence of the collateral channel of sovereign risk forms an amplification mechanism that leads to output losses beyond the fall in aggregate productivity prior to a sovereign default. The deep recessions observed in the euro area in the aftermath of the global financial crisis that preceded the outbreak of the sovereign debt crisis complement this view.

In the period of government default, a freeze on the interbank market leads to an imminent credit crunch and a deep recession. Under the baseline calibration, the model predicts a drop in credit of about 27 percent in response to a complete breakdown of interbank intermediation. As a consequence of the credit crunch and rising cost of capital, output drops by about 19 percent compared to the long-run mean on impact. Although this is a dramatic decline in output, it is not unprecedented in economic history. Reinhart \& Rogoff (2009) document that financial crises lead to output losses of 9.3 percent on average, but have also significantly exceeded this number. ${ }^{43}$ Otherwise, given that the model does not account for financial assistance programmes from EMU member countries, the output losses generated by the model probably poses an upper

\footnotetext{
${ }^{42}$ This result is in line with empirical findings by Levy-Yeyati \& Panizza (2011) who analyse a cross-section of historical default events.

${ }^{43}$ In particular, the US cumulative decline in per capita GDP in response to the Great Depression of 1929 from peak to trough was 29 percent.
} 
bound in the Spanish case. ${ }^{44}$

In the post-crisis period, output recovers slowly. Persistence of production is due to the highly auto-correlated exogenous process of productivity and an endogenous propagation mechanism, as collateral needs to be accumulated by banks out of retained earnings over time. This prevents a fast recovery in lending conditions. Remember from the bank balance sheet identity that collateral assets represent bank capital from an accounting perspective. After a complete write-off of government debt, there is no bank capital left. This poses an extremely large shock on bank balance sheets, which have a difficult time recovering during the low productivity environment following a default. Therefore, the model is supporting the view of long-lasting financial recessions (Cerra \& Saxena 2008) as opposed to a strong recovery observed in the follow-up to emerging market crises (Calvo et al. 2006).

\subsection{Sensitivity analysis and discussion}

In this section we provide further sensitivity analyses in order to underpin the robustness of the quantitative results. Besides, a more detailed discussion of the model propagation mechanism helps to understand the complex interactions of different default incentives at play in the model.

Table 4 presents the results of the sensitivity analysis. Lowering the parameter $\pi^{p}$ to 0.45 increases the need for reallocation of funds across banks on the interbank market, as fewer banks are matched with non-financial firms. With an increasingly important interbank market, a default-related credit crunch gets more destructive, as there are fewer financial resources available to lending banks in the autarky state. As a consequence, the debt-to-GDP ratio more than doubles and exceeds, at 48.5 percent, the observable level in the data, while default occurs less often.

The parameter $\pi^{p}$ can be interpreted as a short cut for financial development or financial institutions which allow a banking system to generate more intermediation. The here presented model with a collateral channel of sovereign risk confirms the findings of Gennaioli et al. (2014) in that an economy with more developed financial institutions is more vulnerable to sovereign defaults.

A reduction in the available financial resources $N$ increases the penalty of default as fewer financial resources are left for credit in the autarky period. The average sustainable level of government indebtedness increases to 26.2 percent. This is the case even though a lower share of total outstanding debt is held domestically, given that fewer financial resources are intermediated on the interbank market. At the same time, a lower value for $N$ pushes up the interest rate on credit as financial resources are more scarce in equilibrium and the spread $\bar{r}^{\kappa}-\bar{r}^{M}$ almost doubles compared to the baseline calibration. When sovereign risk rises due to low productivity realisations, the demand-effect in the premium on credit is now stronger, leading to a less strong correlation of private and public sector interest rates.

Turning to the working capital assumption, we reduce the fraction that needs to be financed up-front to $\eta=0.95$. Note that this change leaves all other parameters from

\footnotetext{
${ }^{44}$ See Fink \& Scholl (2011) and Juessen \& Schabert (2013) for models of sovereign default with a bailout mechanism.
} 
Table 4: Sensitivity analysis

\begin{tabular}{lccccccc}
\hline & $\begin{array}{c}(\mathrm{i}) \\
\text { Debt/GDP }\end{array}$ & $\begin{array}{c}(\mathrm{ii}) \\
\text { Domestic } \\
\text { debt share }\end{array}$ & $\begin{array}{c}\text { (iii) } \\
\text { default } \\
\text { frequ. }\end{array}$ & $\begin{array}{c}(\mathrm{iv}) \\
\bar{r}^{\kappa}-\bar{r}^{M}\end{array}$ & $\begin{array}{c}(\mathrm{v}) \\
\rho\left(\hat{r}_{t}^{g}, Y_{t}\right)\end{array}$ & $\begin{array}{c}(\mathrm{vi}) \\
\rho\left(\hat{r}_{t}^{\kappa}, \hat{r}_{t}^{g}\right)\end{array}$ & $\begin{array}{c}\text { (vii) } \\
\text { Output } \\
\text { drop }\end{array}$ \\
\hline Data & 49.5 & 49.0 & 0.654 & 0.459 & -0.08 & 0.84 & - \\
Baseline & 21.4 & 61.7 & 0.628 & 0.210 & -0.44 & 0.40 & 19.6 \\
\hline$\pi^{p}=0.70$ & 7.0 & 86.7 & 0.397 & 0.320 & 0.21 & 0.43 & 8.3 \\
$\pi^{p}=0.45$ & 48.5 & 47.1 & 0.151 & 0.250 & -0.30 & 0.28 & 28.4 \\
$N=3.15$ & 16.5 & 72.0 & 0.656 & 0.140 & -0.15 & 0.48 & 16.2 \\
$N=2.80$ & 26.2 & 55.3 & 0.437 & 0.350 & -0.51 & 0.33 & 22.3 \\
$\eta=1.25$ & 35.0 & 48.9 & 0.151 & 0.122 & -0.30 & 0.13 & 24.8 \\
$\eta=0.95$ & 12.1 & 78.7 & 0.684 & 0.180 & 0.02 & 0.51 & 13.5 \\
$\omega=1.6$ & 16.2 & 73.5 & 0.616 & 0.140 & -0.05 & 0.55 & 15.0 \\
$\omega=1.3$ & 27.1 & 54.0 & 0.313 & 0.580 & -0.39 & 0.24 & 24.5 \\
$\psi=0.40$ & 21.5 & 61.6 & 0.613 & 0.220 & -0.45 & 0.55 & 19.7 \\
$\psi=0.10$ & 21.6 & 61.8 & 0.630 & 0.180 & -0.43 & 0.22 & 19.9 \\
$\phi=15$ & 19.5 & 63.0 & 0.529 & 0.150 & -0.26 & 0.42 & 18.8 \\
$\phi=3$ & 24.1 & 65.5 & 0.619 & 0.740 & -0.46 & 0.24 & 19.5 \\
$\theta=0.25$ & 16.0 & 82.6 & 0.491 & 0.180 & -0.14 & 0.49 & 18.5 \\
$\chi=0.35$ & 25.7 & 67.7 & 0.626 & 0.270 & -0.43 & 0.24 & 19.7 \\
$\chi=0.15$ & 16.6 & 50.8 & 0.622 & 0.160 & -0.42 & 0.56 & 19.6 \\
\hline
\end{tabular}

Notes: A hat denotes the spread of the corresponding interest rate over the risk-free rate $r^{f}$.

the baseline calibration unaffected. Under these conditions, lowering $\eta$ has a similar effect as increasing $N$, as more financial resources are available in the system in relation to a fall in credit demand. The default penalty from an output drop decreases, making default more likely on average. This, in turn, lowers the ratio of debt-to-GDP in the model.

The parameter $\omega$ governs the Frisch elasticity of labour supply according to $1 /(1-\omega)$. Thereby, increasing $\omega$ translates into lower substitution effects of labour supply in response to changes in the equilibrium wage rate. Remember that the bank-sovereign link unfolds in conjunction with the working capital constraint on labour input, as sovereign risk drives up the price of labour from the perspective of the non-financial firm. Consequently, setting $\omega$ to 1.6, we find that the output cost of default drops, leading to lower levels of debt. As labour supply is less sensitive to a fall in the wage rate given higher values for $\omega$, the distortions arising from the sovereign risk channel can be compensated by lower equilibrium wages.

Lifting the parameter $\psi$ from the baseline calibration of 0.245 to 0.4 intensifies the spillovers from sovereign risk to the cost of funding on domestic interbank markets when the quality of collateral deteriorates. This drives the correlation of risk premiums on public and private sector debt to 0.55 and lightly enforces the counter-cyclical correlation with output.

Increasing $\phi$ reduces the need for excess reserves when borrowing funds on the interbank market. Less severe frictions in the model lead to marginally more financial resources available for working capital credit, as there are fewer productive reserves required to self-insure against roll-over risk. This lowers the negative correlation of the sovereign risk premium with output to -0.26 . 
The parameter governing the stochastic probability of re-entering capital markets $\theta$ might be lower in the Spanish case than in the baseline calibration fitted to a cross-section of emerging market economies, as international investors might put more confidence into the institutional setting in the euro area. ${ }^{45}$ To check for the effects of a faster re-access to capital markets, we set the re-entry probability to $\theta=0.25$, which represents an average exclusion spell of one year. As this constitutes a direct reduction of costs of default, the debt-to-GDP level shrinks in the long-run average. With fewer government securities available in the economy, the share of domestic debt rises.

At very low levels of $\chi$, domestic banks draw higher liquidity services per unit of government bonds. At the same time, the demand for liquidity services is limited in the model given a downward sloping demand curve for credit and interbank loans. In sum, the domestic share of total government debt drops in the stochastic stationary state compared with the baseline calibration. Non-penalty related repayment incentives on the side of the government are reduced, which translates into an overall smaller ratio of sustainable public debt to output. We conclude that non-penalty related incentives to repay creditors might be an important explanation for high debt-to-GDP ratios observed in the data of advanced economies. ${ }^{46}$

\section{Conclusion}

In this paper, we propose a model of strategic default for advanced, financially developed economies that accounts for the bank-sovereign link in a dynamic stochastic general equilibrium setting. The model is calibrated to Spanish data and capable of reproducing business cycle statistics alongside stylized facts from the European sovereign debt crisis.

The results show that the adverse feedback loop in peripheral euro area countries between a dysfunctional interbank market, a weak growth performance, and a rise in sovereign bond yield spreads can be rationalised by the concept of strategic default. In the presence of spillovers from sovereign risk to financial market outcomes, an otherwise high default penalty loses its disciplinary role and introduces fragility into advanced countries' public debt positions. The model is able to explain the impairment of credit conditions along national borders due to the collateral channel of sovereign risk on the secured interbank market.

Domestically held government debt introduces a motive for government borrowing by providing liquidity services to the economy, which has not been considered in the quantitative literature on optimal sovereign default. As a result, the borrowing limit becomes more responsive to transitory productivity shocks, while at the same time sustaining higher aggregate levels of debt. Further, we find that it is the net for-

\footnotetext{
${ }^{45}$ For Greece, it took more then two years after the pre-emptive debt restructuring in February 2012 until the first bond issuance in April 2014.

${ }^{46}$ Anecdotal evidence points into this direction, as the examples of Italy and Japan indicate, which both exhibit very high ratios of debt-to-GDP and depend on a domestic investor base. Moreover, there is evidence in the European sovereign debt crisis that the repatriation of debt is lowering default risk (Brutti \& Sauré 2013).
} 
eign asset position of an economy that determines incentives under strategic default considerations.

There are limitations to this framework. Specifically, the model abstracts from many relevant questions surrounding the decision to default, as debt renegotiation (Yue 2010, Bai \& Zhang 2012), the maturity structure of debt (Hatchondo \& Martinez 2009, Arellano \& Ramanarayanan 2012, Chatterjee \& Eyigungor 2012), the effects of international financial assistance programs (Boz 2011, Fink \& Scholl 2011, Juessen \& Schabert 2013), international spillovers (Arellano \& Bai 2013), and redistributive effects of default on domestic debt (D'Erasmo \& Mendoza 2012). Further research is also required to deepen our understanding of the interactions of sovereign risk with other sources of bank funding. Finally, we leave it for future research to investigate financial sector stabilisation policies through the central bank. 


\section{References}

Acharya, V., Drechsler, I. \& Schnabl, P. (2014), 'A Pyrrhic Victory? Bank Bailouts and Sovereign Credit Risk', The Journal of Finance .

Acharya, V. V. \& Rajan, R. G. (2013), 'Sovereign debt, government myopia, and the financial sector', Review of Financial Studies 26(6), 1526-1560.

Aguiar, M. \& Gopinath, G. (2006), 'Defaultable debt, interest rates and the current account', Journal of International Economics 69, 64-83.

Arellano, C. (2008), 'Default risk and income fluctuations in emerging economies', American Economic Review 98(3), 690-712.

Arellano, C. \& Bai, Y. (2013), 'Linkages across sovereign debt markets', NBER Working Paper (19548).

Arellano, C. \& Ramanarayanan, A. (2012), 'Default and the maturity structure in sovereign bonds', Journal of Political Economy 120(2), 187-232.

Arslanalp, S. \& Tsuda, T. (2012), 'Tracking global demand for advanced economy sovereign debt', IMF Working Paper (284).

Bai, Y. \& Zhang, J. (2012), 'Duration of sovereign debt renegotiation', Journal of International Economics 86(86), 252-268.

Baltensperger, E. (1980), 'Alternative approaches to the theory of the banking firm', Journal of Monetary Economics 6(1), 1-37.

Barro, R. J. (1976), 'The loan market, collateral, and rates of interest', Journal of Money, Credit and Banking 8(4), 439-456.

Beber, A., Brandt, M. W. \& Kavajecz, K. A. (2009), 'Flight-to-quality or flight-toliquidity? Evidence from the euro-area bond market', Review of Financial Studies 22(3), 925-957.

Bernoth, K. \& Erdogan, B. (2012), 'Sovereign bond yield spreads: A time-varying coeficient approach', Journal of International Money and Finance 31(3), 639-659.

BIS (2011), 'The impact of sovereign credit risk on bank funding conditions', CGFS Papers (43).

Bolton, P. \& Jeanne, O. (2011), 'Sovereign default risk and bank fragility in financially integrated economies', IMF Economic Review (59), 162-194.

Boz, E. (2011), 'Sovereign default, private sector creditors, and the IFIs', Journal of International Economics 83(1), 70-82.

Broner, F. A., Erce, A., Martin, A. \& Ventura, J. (2014), 'Secondary markets in turbulent times: Creditor discrimination and crowding-out effects', Journal of Monetary Economics 61, 114-142. 
Broner, F. A., Martin, A. \& Ventura, J. (2010), 'Sovereign risk and secondary markets', American Economic Review 100(4), 1523-1555.

Brutti, F. (2011), 'Sovereign defaults and liquidity crises', Journal of International Economics 84(1), 65-72.

Brutti, F. \& Sauré, P. (2013), 'Repatriation of debt in the euro crisis: Evidence for the secondary market theory', SSRN Working Paper (2253404).

Bulow, J. \& Rogoff, K. S. (1989), 'Sovereign debt: Is to forgive to forget?', American Economic Review 79(1), 43-50.

Calvo, G. A., Izquierdo, A. \& Talvi, E. (2006), 'Sudden stops and phoenix miracles in emerging markets', American Economic Review: Papers $\&$ Proceedings 96(2), 405410.

Cerra, V. \& Saxena, S. C. (2008), 'Growth dynamics: The myth of economic recovery', American Economic Review 98(1), 439-457.

Chari, V. V., Christiano, L. J. \& Eichenbaum, M. (1995), 'Inside money, outside money, and short-term interest rates', Journal of Money, Credit and Banking 27(4), 1354-1386.

Chatterjee, S. \& Eyigungor, B. (2012), 'Maturity, indebtedness, and default risk', American Economic Review 102(6), 2674-2699.

Christiano, L. J., Motto, R. \& Rostagno, M. (2010), 'Financial factors in economic fluctuations', ECB Working Paper Series (1192).

Cole, H. L. \& Kehoe, P. J. (1998), 'Models of sovereign debt: Partial versus general reputations', International Economic Review 39(1), 50-77.

Cuadra, G., Sanchez, J. \& Sapriza, H. (2010), 'Fiscal policy and default risk in emerging markets', Review of Economic Dynamics 13(2), 452-469.

Dang, T. V., Gorton, G. \& Holmström, B. (2013), 'The information sensitivity of a security'.

Dell'ariccia, G., Detragiache, E. \& Rajan, R. G. (2005), 'The real effect of banking crises', IMF Working Paper (63).

D'Erasmo, P. \& Mendoza, E. G. (2012), 'Domestic sovereign default as optimal redistributive policy', Unpublished Manuscript, University of Pennsylvania .

Diamond, D. W. (1984), 'Financial intermediation and delegated monitoring', Review of Economic Studies 51, 393-414.

Dooley, M. P. (2000), 'International financial architecture and strategic default: Can financial crises be less painful?', Carnegie-Rochester Conference Series on Public Policy 53, 361-377. 
Eaton, J. \& Gersovitz, M. (1981), 'Debt with potential repudiation: Theoretical and empirical analysis', Review of Economic Studies 48(2), 289-309.

Ejsing, J. \& Lemke, W. (2011), 'The Janus-headed salvation: Sovereign and bank credit risk premia during 2008-2009', Economics Letters 110(1), 28-31.

European Central Bank (2012), 'Changes in bank financing patterns', Frankfurt a. M.

European Central Bank (2013), 'Banking structures report', Frankfurt a. M.

Fernández, A. \& Gulan, A. (2012), 'Interest rates and business cycles in emerging economies: The role of financial frictions', Bank of Finland Research Discussion Papers (23).

Fink, F. \& Scholl, A. (2011), 'A quantitative model of sovereign debt, bailouts, and conditionality', Working Paper Series, University of Konstanz (2011-46).

Gennaioli, N., Martin, A. \& Rossi, S. (2014), 'Sovereign default, domestic banks, and financial institutions', Journal of Finance 69(2), 819-866.

Gertler, M. \& Kiyotaki, N. (2011), Financial intermediaries and credit policy in business cycle analysis, in B. Friedman \& M. Woodford, eds, 'Handbook of Monetary Economics', Elsevier, North-Holland, pp. 547-599.

Giannone, D., Lenza, M., Pill, H. \& Reichlin, L. (2012), 'The ECB and the interbank market', ECB Working Paper Series (1496).

Gorton, G. B. \& Metrick, A. (2012), 'Securitized banking and the run on repo', Journal of Financial Economics 104(3), 425-451.

Gorton, G. B. \& Ordoñez, G. (2013), 'The supply and demand for safe assets', NBER Working Paper (18732).

Greenwood, J., Hercowitz, Z. \& Huffman, G. W. (1988), 'Investment, capital utilization, and the real business cycle', American Economic Review 78(3), 402-417.

Grossman, H. I. \& van Huyck, J. B. (1988), 'Sovereign debt as a contingent claim: Excusable default, repudiation, and reputation', American Economic Review 78(5), 1088-1097.

Guembel, A. \& Sussman, O. (2009), 'Sovereign debt without default penalties', Review of Economic Studies 76, 1297-1320.

Hatchondo, J. C. \& Martinez, L. (2009), 'Long-duration bonds and sovereign defaults', Journal of International Economics 79(1), 117-125.

Hatchondo, J. C., Martinez, L. \& Sapriza, H. (2010), 'Quantitative properties of sovereign default models: Solution methods matter', Review of Economic Dynamics 13(4), 919-933.

Holmström, B. \& Tirole, J. (1998), 'Private and public supply of liquidity', Journal of Political Economy 106(1), 1-40. 
ICMA (2013), 'European repo market survey: Number 25 - conducted June 2013: International Capital Market Association', Zurich.

Juessen, F. \& Schabert, A. (2013), 'Fiscal policy, sovereign default, and bailouts', Unpublished Manuscript .

Krishnamurthy, A. \& Vissing-Jorgensen, A. (2012), 'The aggregate demand for treasury debt', Journal of Political Economy 120(2), 233-267.

Kumhof, M. \& Tanner, E. (2008), Government debt: A key role in financial intermediation, in C. M. Reinhart, C. A. Vegh \& A. Velasco, eds, 'Money, crises, and transition', MIT Press, Cambridge and Mass., pp. 249-278.

Levy-Yeyati, E. \& Panizza, U. (2011), 'The elusive costs of sovereign defaults', Journal of Development Economics 94(1), 95-105.

Lizarazo, S. V. (2013), 'Default risk and risk averse international investors', Journal of International Economics 89, 317-330.

Mendoza, E. G. \& Yue, V. Z. (2012), 'A general equilibrium model of sovereign default and business cycles', Quarterly Journal of Economics (127), 889-946.

Neumeyer, P. A. \& Perri, F. (2005), 'Business cycles in emerging economies: The role of interest rates', Journal of Monetary Economics 52(2), 345-380.

Niemann, S. \& Pichler, P. (2013), 'Collateral, liquidity and debt sustainability', Discussion Paper Series of the University of Essex (730).

Padilla, C. S. (2013), 'Sovereign defaults and banking crises', MPRA Working Paper (41074).

Poole, W. (1968), 'Commercial bank reserve management in a stochastic model: Implications for monetary policy', Journal of Finance 23(5), 769-791.

Pouzo, D. \& Presno, I. (2013), 'Sovereign default risk and uncertainty premia', SSRN Working Paper.

Reinhart, C. M. \& Rogoff, K. S. (2009), 'The aftermath of financial crises', American Economic Review: Papers \& Proceedings 99(2), 466-472.

Reinhart, C. M. \& Rogoff, K. S. (2011), 'The forgotten history of domestic debt', The Economic Journal (121), 319-350.

Richmond, C. \& Dias, D. A. (2009), 'Duration of capital market exclusion: An empricial investigation', SSRN Working Paper.

Sandleris, G. (2014), 'Sovereign defaults, credit to the private sector, and domestic credit market institutions', Journal of Money, Credit and Banking 46(2-3), 321345 .

Schmitt-Grohé, S. \& Uribe, M. (2007), 'Optimal, simple, and implementable monetary and fiscal rules', Journal of Monetary Economics 54, 702-1725. 
Smets, F. \& Wouters, R. (2002), 'An estimated stochastic dynamic general equilibium model of the Euro area', ECB Working Paper Series (171).

Sturzenegger, F. \& Zettelmeyer, J. (2007), Debt, defaults and lessons from a decade of crises, MIT Press, Cambridge Mass.

Tauchen, G. (1986), 'Finite state Markov-chain approximations to univariate and vector autoregressions', Economics Letters 20, 177-181.

Tomz, M. \& Wright, M. L. J. (2007), 'Do countries default in bad times?', Journal of the European Economic Association 5(2-3), 352-360.

Uribe, M. \& Yue, V. Z. (2006), 'Country spreads and emerging countries: Who drives whom?', Journal of International Economics 69, 6-36.

Woodford, M. (1990), 'Public debt as private liquidity', American Economic Review: Papers 8 Proceedings 80(2), 382-388.

Yue, V. Z. (2010), 'Sovereign default and debt renegotiation', Journal of International Economics 80(2), 176-187.

Zame, W. R. (1993), 'Efficiency and the role of default when security markets are incomplete', American Economic Review 83(5), 1142-1164. 


\section{A Proofs}

Proof of Proposition 1. In order that a representative bank for each type exists, the proof has to show (i) that aggregated collateral holding is identical to the probability mass $\pi^{\tau}$; and (ii) that the distribution of collateral within each type $\tau$ does not affect individual decisions.

Step (i) By assumption it holds that each bank retains an identical amount of liquid financial resources from dividend payments and collateral purchases, i.e. for $i \neq j$ it holds that $N_{i}^{\tau}=N_{j}^{\tau}$ for all $\tau \in\{p, u\}$. It follows that $\int_{0}^{\pi^{\tau}} N_{i}^{\tau} d i=\pi^{\tau} N$. Returns on investment opportunities are equal across idiosyncratic banks, hence each bank takes identical choices over credit and interbank allocations given identical holdings of collateral assets and endowment of liquid assets $N_{j}^{\tau}$. Although $D_{t=0}^{p} \neq D_{t=0}^{u}$, it follows from the independent and identically distributed funding shock $\tau \in\{p, u\}$ jointly with the law of large numbers that $\int_{0}^{\pi^{\tau}} B_{t, i}^{D, \tau} d i=\pi^{\tau} B_{t}^{D}$. Step (ii) From the linearity in the profit maximisation problem of banks follows that individual decisions are independent of the distribution of collateral.

Proof of Proposition 2. The proof is fulfilled by the first-order-necessary condition on bond purchases by banks in the model equilibrium according to equation (C.3).

Proof of Proposition 3. The proof is derived from the profit maximisation problem of risk-neutral international investors. The expected pay-off on bonds is denoted by $E_{t}\left(1-\delta_{t+1}\right)$, which is discounted by a risk-free interest rate $r^{f}$. International investors maximise expected returns on investment, subject to the market clearing condition on secondary markets from equation (9)

$$
\begin{array}{ll} 
& \max _{\left\{B_{t+1}^{D}\right\}} \Pi_{t}^{*}=\tilde{q}_{t} B_{t+1}^{D}+B_{t+1}^{*} E_{t}\left(\frac{1-\delta_{t+1}}{1+r^{f}}\right), \\
\text { s.t. } & B_{t+1}+B_{t+1}^{D}+B_{t+1}^{*}=0, \\
& B_{t+1}^{D} \geq 0 .
\end{array}
$$

The first-order condition for bond supply of international investors yields the noarbitrage condition

$$
\tilde{q}_{t}=E_{t}\left(\frac{1-\delta_{t+1}}{1+r^{f}}\right)+\mu_{t}^{B^{D}}
$$

where the Lagrange multiplier on the constraint $\mu_{t}^{B^{D}}$ is zero due to the price-taking behaviour of investors on secondary markets. Using equation (32) yields the condition $\tilde{q}_{t}=q_{t}$, which implies a perfectly elastic supply of bonds from international investors at a secondary market price $\tilde{q}_{t}$ which is identical to the primary market price $q_{t}$.

Proof of Proposition 4. Denote the set of possible productivity realisations by $A_{t} \in \mathbb{A}$ and an endogenous state by $\epsilon_{t}^{n} \equiv\left(B_{t}^{n}, \bar{B}_{t}^{D}\right)$, where $n$ indicates different values 
of total debt that satisfy the condition $\left|B_{t}^{n}\right| \geq \bar{B}_{t}^{D}$. From state $\epsilon_{t}^{2} \in \Gamma_{t}^{\delta}$ follows

$$
\begin{aligned}
V_{t}^{d}\left(\epsilon_{t}^{2}, A_{t}\right)=U\left(C_{t}, 1-L_{t}\right)+\beta E_{t}\left[\theta V_{t+1}^{n d}\left(0,0, A_{t+1}\right)+(1-\theta) V_{t+1}^{d}\left(0,0, A_{t+1}\right)\right] \\
>U\left(C_{t}, 1-L_{t}\right)+\beta E_{t}\left[\mathcal{V}_{t+1}\left(B_{t+1}^{2}, \bar{B}_{t+1}^{D}, A_{t+1}\right)\right]=V_{t}^{n d}\left(\epsilon_{t}^{2}, A_{t}\right) .
\end{aligned}
$$

Claim: The default value is independent of the endogenous state, i.e.

$$
V_{t}^{d}\left(\epsilon_{t}^{1}, A_{t}\right)=V_{t}^{d}\left(\epsilon_{t}^{2}, A_{t}\right) \forall A_{t} \in \mathbb{A}
$$

Proof of Claim: The independence of equilibrium allocations under default from $\epsilon_{t}$ follows directly from the definition of the partial equilibrium under default in Section 3.6 in combination with the aggregate resource constraint (31).

Next, consider a state $\epsilon_{t}^{1}$ such that $B_{t}^{1}<B_{t}^{2}$. Trivially, this implies $B_{t}^{1}+\bar{B}_{t}^{D}<$ $B_{t}^{2}+\bar{B}_{t}^{D} \leq 0$ from the market clearing condition on secondary markets (9). Conditional on the repayment equilibrium, it follows from the aggregate resource constraint that for any pair of choices $\left\{B_{t+1}, B_{t+1}^{D}\right\}$ that satisfies the conditions above one obtains $C_{t}\left(\epsilon_{t}^{1}, A_{t}\right)<C_{t}\left(\epsilon_{t}^{2}, A_{t}\right)$. This implies from the equilibrium condition for labour supply from equation (2) that the marginal disutility from labour is higher in the state with low total debt:

$$
\begin{aligned}
\frac{\partial U_{t}}{\partial C_{t}}\left(\epsilon_{t}^{2}\right) & =-\frac{\partial U_{t}}{\partial L_{t}}\left(\epsilon_{t}^{2}\right) \text { and } \quad \frac{\partial U_{t}}{\partial C_{t}}\left(\epsilon_{t}^{1}\right)=-\frac{\partial U_{t}}{\partial L_{t}}\left(\epsilon_{t}^{1}\right) \\
\text { Thus } \quad \frac{\partial U_{t}}{\partial C_{t}}\left(\epsilon_{t}^{2}\right) & <\frac{\partial U_{t}}{\partial C_{t}}\left(\epsilon_{t}^{1}\right) \\
\Rightarrow \quad-\frac{\partial U_{t}}{\partial L_{t}}\left(\epsilon_{t}^{2}\right) & >-\frac{\partial U_{t}}{\partial L_{t}}\left(\epsilon_{t}^{1}\right),
\end{aligned}
$$

where the conclusion is derived from the decreasing marginal rate of utility from consumption given the standard properties of the utility function from Section 4.1. Hence, $V_{t}^{n d}\left(B_{t}^{2}, \bar{B}_{t}^{D}, A_{t}\right)>V_{t}^{n d}\left(B_{t}^{1}, \bar{B}_{t}^{D}, A_{t}\right)$, and therefore $\epsilon_{t}^{1}=\left(B_{t}^{1}, \bar{B}_{t}^{D}\right) \in \Gamma_{t}^{\delta} \forall A_{t} \in \mathbb{A}: \epsilon_{t}^{2} \in$ $\Gamma_{t}^{\delta}$.

Proof of Proposition 5. This proof closely follows the steps in the proof of Proposition 4 .

Denote the set of possible productivity realisations by $A_{t} \in \mathbb{A}$ and an endogenous state by $\epsilon_{t}^{n} \equiv\left(\bar{B}_{t}, B_{t}^{D, n}\right)$ where $n$ is an index for values of domestic debt. From state $\epsilon_{t}^{2} \in \Gamma_{t}^{\delta}$ follows

$$
\begin{aligned}
V_{t}^{d}\left(\epsilon_{t}^{2}, A_{t}\right)= & U\left(C_{t}, 1-L_{t}\right)+\beta E_{t}\left[\theta V_{t+1}^{n d}\left(0,0, A_{t+1}\right)+(1-\theta) V_{t+1}^{d}\left(0,0, A_{t+1}\right)\right] \\
& >U\left(C_{t}, 1-L_{t}\right)+\beta E_{t}\left[\mathcal{V}_{t+1}\left(\bar{B}_{t+1}, B_{t+1}^{D, 2}, A_{t+1}\right)\right]=V_{t}^{n d}\left(\epsilon_{t}^{2}, A_{t}\right)
\end{aligned}
$$

Next, consider a state $\epsilon_{t}^{1}$ such that $B_{t}^{D, 1}<B_{t}^{D, 2} \leq\left|\bar{B}_{t}\right|$ which implies $\bar{B}_{t}+B_{t}^{D, 1}<$ $\bar{B}_{t}+B_{t}^{D, 2} \leq 0$. Conditional on the repayment equilibrium, it follows that for any pair of choices $\left\{B_{t+1}, B_{t+1}^{D}\right\}$ one obtains $C_{t}\left(\epsilon_{t}^{1}, A_{t}\right)<C_{t}\left(\epsilon_{t}^{2}, A_{t}\right)$. This implies from the equilibrium condition for labour supply from equation (2) that the marginal disutility 
from labour is lower in the state with higher domestic debt:

$$
\begin{aligned}
\frac{\partial U_{t}}{\partial C_{t}}\left(\epsilon_{t}^{2}\right) & =-\frac{\partial U_{t}}{\partial L_{t}}\left(\epsilon_{t}^{2}\right) \text { and } \quad \frac{\partial U_{t}}{\partial C_{t}}\left(\epsilon_{t}^{1}\right)=-\frac{\partial U_{t}}{\partial L_{t}}\left(\epsilon_{t}^{1}\right) \\
\text { Thus } \quad \frac{\partial U_{t}}{\partial C_{t}}\left(\epsilon_{t}^{2}\right) & <\frac{\partial U_{t}}{\partial C_{t}}\left(\epsilon_{t}^{1}\right) \\
\Rightarrow \quad-\frac{\partial U_{t}}{\partial L_{t}}\left(\epsilon_{t}^{2}\right) & >-\frac{\partial U_{t}}{\partial L_{t}}\left(\epsilon_{t}^{1}\right),
\end{aligned}
$$

Hence, $V_{t}^{n d}\left(\bar{B}_{t}, B_{t}^{D, 2}, A_{t}\right)>V_{t}^{n d}\left(\bar{B}_{t}, B_{t}^{D, 1}, A_{t}\right)$, and therefore $\epsilon_{t}^{1}=\left(\bar{B}_{t}, B_{t}^{D, 1}\right) \in \Gamma_{t}^{\delta} \forall A_{t} \in$ $\mathbb{A}: \epsilon_{t}^{2} \in \Gamma_{t}^{\delta}$.

Proof of Proposition 6. Given are the two choices over period $t+1$ endogenous states $\epsilon_{t+1}^{1} \equiv\left(\bar{B}_{t+1}, B_{t+1}^{D, 1}\right)$, and $\epsilon_{t+1}^{2} \equiv\left(\bar{B}_{t+1}, B_{t+1}^{D, 2}\right)$. From Proposition 5 follows directly that $\Gamma_{t+1}^{\delta}\left(\epsilon_{t+1}^{1}\right) \subseteq \Gamma_{t+1}^{\delta}\left(\epsilon_{t+1}^{2}\right) \forall A_{t+1} \in \mathbb{A}: \epsilon_{t+1}^{2} \in \Gamma_{t+1}^{\delta}$. (i) Applying the definition of the default probability, one gets $\pi_{t}^{\delta}\left(\epsilon_{t+1}^{2}, A_{t}\right) \leq \pi_{t}^{\delta}\left(\epsilon_{t+1}^{1}, A_{t}\right)$. (ii) Using the pricing equation of international investors $(27)$ yields $q_{t}\left(\epsilon_{t+1}^{2}, A_{t}\right) \geq q_{t}\left(\epsilon_{t+1}^{1}, A_{t}\right)$. 


\section{B Timeline}

Figure 10: Timeline of events

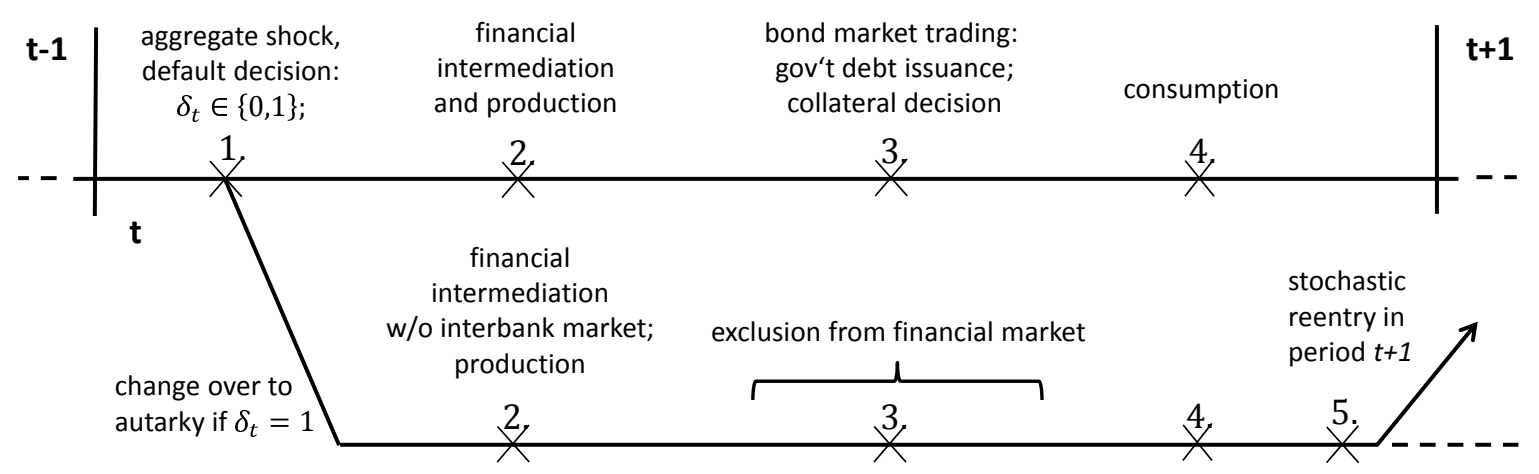




\section{Model Appendix}

\section{C.1 Bank optimization}

\section{C.1.1 Productive banks}

$$
\max _{\left\{B_{j, t+1}^{D, p}, \kappa_{j, t}, M_{j, t}, R_{j, t}^{e}, R_{j, t}^{d, p}\right\}} E_{t}\left[\sum_{i=0}^{\infty} \beta^{b^{i}} D_{j, t+i}^{p}\right]
$$

with

$$
\begin{array}{ll}
N_{j}^{p}+D_{j, t}^{p} & =\underbrace{\left(1-\delta_{t}\right) B_{j, t}^{D, p}+\left(1+r_{t}^{\kappa}\right) \kappa_{j, t}-\left(1+r_{t}^{M}\right) M_{j, t}+\left(1+r^{R}\right) R_{j, t}^{p}}_{\equiv \text { type } p \text { period } t \text { cashflows, } X_{j, t}^{p}}-\left(1-\delta_{t}\right) q_{t} B_{j, t+1}^{D, p} \\
\text { s.t. } & N_{j}^{p}+M_{j, t}=\kappa_{j, t}+R_{j, t}^{p} \\
& R_{j, t}^{e}=\frac{M_{j, t}}{\phi} \\
& R_{j, t}^{p}=R_{j, t}^{e}+R_{j, t}^{d, p} \\
& M_{j, t} \leq \frac{\left(1-\delta_{t}\right) B_{j, t}^{D, p}}{\chi} \\
& R_{j, t}^{d, p}, D_{j, t}^{d}, B_{j, t+1}^{D, p} \geq 0
\end{array}
$$

\section{C.1.2 Unproductive banks}

$$
\max _{\left\{B_{j, t+1}^{D, u}, M_{j, t}, R_{j, t}^{d, u}\right\}} E_{t}\left[\sum_{i=0}^{\infty} \beta^{b^{i}} D_{j, t+i}^{u}\right]
$$

with

$$
\begin{gathered}
N_{j}^{u}+D_{j, t}^{u}=\underbrace{\left(1-\delta_{t}\right) B_{j, t}^{D, u}+\left(1+r_{t}^{M}\right) M_{j, t}+\left(1+r^{R}\right) R_{j, t}^{u}}_{\equiv \text { type } u \text { period } t \text { cashflows, } X_{j, t}^{u}}-\left(1-\delta_{t}\right) q_{t} B_{j, t+1}^{D, p} \\
\text { s.t. } \quad N_{j}^{u}=M_{j, t}+R_{j, t}^{u} \\
R_{j, t}^{u}=R_{j, t}^{d, u} \\
R_{j, t}^{d, u}, D_{j, t}^{d}, B_{j, t+1}^{D, u} \geq 0
\end{gathered}
$$

Note that subscripts $j$ for individual banks can be ignored due to the existence of a representative bank for each type $\tau \in\{p, u\}$, according to Proposition 1 . 


\section{C.1.3 Recursive notation: Set of bank value functions}

Rewrite the maximization problems of banks from (C.1) and (C.2) in recursive form as

$$
\begin{gathered}
\mathcal{W}^{p}\left(B_{t}, B_{t}^{D}, A_{t}\right)=\underset{\left\{B_{t+1}^{D, p}, \kappa_{t}, M_{t}, R_{t}^{e}, R_{t}^{d, p}\right\}}{\max } D_{t}^{p}\left(B_{t}, B_{t}^{D}, A_{t}\right)+\beta^{b} E_{t}\left[\mathcal{W}\left(B_{t+1}, B_{t+1}^{D}, A_{t+1}\right)\right] \\
\mathcal{W}^{u}\left(B_{t}, B_{t}^{D}, A_{t}\right)=\max _{\left\{B_{t+1}^{D, u}, M_{t}, R_{t}^{d, u}\right\}} D_{t}^{u}\left(B_{t}, B_{t}^{D}, A_{t}\right)+\beta^{b} E_{t}\left[\mathcal{W}\left(B_{t+1}, B_{t+1}^{D}, A_{t+1}\right)\right]
\end{gathered}
$$

Denote the expected continuation value of banks in period $t$ under i.i.d. probability of taking type $\tau \in\{p, u\}$ next period as

$$
E_{t}\left[\mathcal{W}\left(B_{t+1}, B_{t+1}^{D}, A_{t+1}\right)\right]=E_{t}\left[\pi^{p} \mathcal{W}^{p}\left(B_{t+1}, B_{t+1}^{D}, A_{t+1}\right)+\pi^{u} \mathcal{W}^{u}\left(B_{t+1}, B_{t+1}^{D}, A_{t+1}\right)\right]
$$

\section{C.1.4 Optimality conditions}

\section{C.1.5 Productive banks}

Forming the Lagrangian by combining (C.1) and (C.3):

$$
\begin{aligned}
\mathcal{L}^{p}= & \max _{\left\{B_{t+1}^{D, p}, \kappa_{t}, R_{t}^{e}, R_{t}^{d, p}\right\}}\left(1-\delta_{t}\right) B_{t}^{D, p}+\left(1+r_{t}^{\kappa}\right) \kappa_{t}-\left(1+r_{t}^{M}\right) \phi R_{t}^{e}+\left(1+r^{R}\right)\left(R_{t}^{e}+R_{t}^{d, p}\right) \\
& -\left(1-\delta_{t}\right) q_{t} B_{t+1}^{D, p}-N^{p}+\eta_{t}^{p}\left(N^{p}+\phi R_{t}^{e}-\kappa_{t}-R_{t}^{e}-R_{t}^{d, p}\right)+\lambda_{t}\left(\left(1-\delta_{t}\right) B_{t}^{D, p}-\chi \phi R_{t}^{e}\right) \\
& +\mu_{t}^{p}\left(R_{t}^{d, p}-0\right)+\beta^{b} E_{t}\left[\mathcal{W}\left(B_{t+1}, B_{t+1}^{D}, A_{t+1}\right)\right]+\mu_{t}^{D, p}\left(0+D_{t}^{p}\right)+\mu^{B_{t}^{D, p}}\left(0+B_{t+1}^{D, p}\right)
\end{aligned}
$$

with Lagrange multipliers for the collateral constraint $\lambda_{t}$, the balance sheet constraint $\eta_{t}^{p}$, the non-negativity constraint on the deposit facility $\mu_{t}^{p}$, dividends $\mu_{t}^{D, p}$, and collateral purchases $\mu_{t}^{B^{D, p}}$, respectively. Interbank loans have been substituted.

The first-order necessary conditions w.r.t. $\left(\kappa_{t}, R_{t}^{e}, R_{t}^{d, p}, B_{t+1}^{D, p}\right)$ are

$$
\begin{gathered}
1+r_{t}^{\kappa}=\eta_{t}^{p} \\
\left(1+r^{R}\right)-\eta^{p}=\phi\left(1+r^{M}+\lambda_{t} \chi-\eta^{p}\right) \\
\left(1+r^{R}\right)+\mu_{t}^{p}=\eta_{t}^{p} \\
\left(1-\delta_{t}\right) q_{t}=\beta^{b} E_{t}\left[\mathcal{W}_{B^{D}}\left(B_{t+1}, B_{t+1}^{D}, A_{t+1}\right)\right]+\mu_{t}^{D, p}
\end{gathered}
$$


with complementary slackness conditions

$$
\begin{aligned}
\lambda_{t}\left(0-\chi M_{t}-\left(1-\delta_{t}\right) B_{t}^{D, p}\right) & =0 \\
\mu_{t}^{p}\left(0+R_{t}^{d, p}\right) & =0 \\
\mu_{t}^{D, p}\left(0+D_{t}^{p}\right) & =0 \\
\mu_{t}^{B^{D, p}}\left(0+B_{t+1}^{D, p}\right) & =0 \\
\lambda_{t}, \eta_{t}^{p}, \mu_{t}^{p}, \mu_{t}^{D, p}, \mu_{t}^{B^{D, p}} & \geq 0
\end{aligned}
$$

\section{C.1.6 Unproductive banks}

Forming the Lagrangian by combining (C.2) and (C.4):

$$
\begin{aligned}
\mathcal{L}^{u}= & \max _{\left\{B_{t+1}^{D, u}, M_{t}, R_{t}^{d, u}\right\}}\left(1-\delta_{t}\right) B_{t}^{D, u}+\left(1+r^{M}\right) M_{t}+\left(1+r^{R}\right) R_{t}^{d, u}-\left(1-\delta_{t}\right) q_{t} B_{t+1}^{D, p}-N^{u} \\
& +\eta_{t}^{u}\left(N^{u}-M_{t}-R_{t}^{d, u}\right)+\mu_{t}^{u}\left(R_{t}^{d, u}-0\right)+\beta^{b} E_{t}\left[\mathcal{W}\left(B_{t+1}, B_{t+1}^{D}, A_{t+1}\right)\right] \\
& +\mu_{t}^{D, u}\left(0+D_{t}^{u}\right)+\mu_{t}^{B^{D, u}}\left(0+B_{t+1}^{D, u}\right)
\end{aligned}
$$

with Lagrange multipliers for the balance sheet constraint $\eta_{t}^{u}$, and the non-negativity constraints on central bank deposits $\mu_{t}^{u}$, dividends $\mu_{t}^{D, u}$, and collateral purchases $\mu_{t}^{B^{D, u}}$, respectively. We use the following functional form for $\Psi\left(q_{t}\right)$ :

$$
\begin{aligned}
\Psi\left(q_{t}\right) & =\psi\left(r_{t}^{g}-r^{f}\right), \\
\text { with } \quad r_{t}^{g} & \equiv q_{t}^{-1}-1
\end{aligned}
$$

From the definition of the interbank rate $r_{t}^{M} \equiv 1+r^{R}+\Psi\left(q_{t}\right)$, we get

$$
r_{t}^{M}=1+r^{R}+\psi\left(r_{t}^{g}-r^{f}\right)
$$

The first-order necessary conditions w.r.t. $\left(M_{t}, R_{t}^{d, u}, B_{t+1}^{D, u}\right)$ are

$$
\begin{gathered}
1+r_{t}^{M}=\eta_{t}^{u} \\
\left(1+r^{R}\right)+\mu_{t}^{u}=\eta_{t}^{u} \\
\left(1-\delta_{t}\right) q_{t}=\beta^{b} E_{t}\left[\mathcal{W}_{B^{D}}\left(B_{t+1}, B_{t+1}^{D}, A_{t+1}\right)\right]+\mu_{t}^{D, u}+\mu_{t}^{B^{D, u}}
\end{gathered}
$$

and the complementary slackness conditions

$$
\begin{aligned}
\mu_{t}^{u}\left(0+R_{t}^{d, u}\right) & =0 \\
\mu_{t}^{D, u}\left(0+D_{t}^{u}\right) & =0 \\
\mu_{t}^{B^{D, u}}\left(0+B_{t+1}^{D, u}\right) & =0 \\
\eta_{t}^{u}, \mu_{t}^{u}, \mu_{t}^{D, u}, \mu_{t}^{B^{D, u}} & \geq 0
\end{aligned}
$$




\section{C.2 Partial equilibrium}

We find $\left\{A_{t}, B_{t}, B_{t}^{D}\right\}$ from the state space. Bond prices $\left\{q_{t}\right\}$ are taken as given. This yields the interbank rate as

$$
r_{t}^{M}=r^{R}+\psi\left(q_{t}^{-1}-1-r^{f}\right)
$$

Using all static optimality conditions derived above, the following nonlinear constrained system of equations yields a solution to the unknowns $\left\{L_{t}, W_{t}, r_{t}^{\kappa}, \kappa_{t}, M_{t}\right.$, $\left.R_{t}^{e}, R_{t}^{d, p}, R_{t}^{d, u}, \lambda_{t}, \mu_{t}^{p}, \mu_{t}^{u}\right\}:$

Equality constraints

$$
\begin{aligned}
M_{t} & =\phi R_{t}^{e} \\
W_{t} & =L_{t}^{\omega-1} \\
\kappa_{t} & =\eta W_{t} L_{t} \\
(1-\alpha) e^{A_{t}} K^{\alpha} L_{t}^{-\alpha} & =W_{t}\left(1+\eta r_{t}^{\kappa}\right) \\
r_{t}^{\kappa}-r^{R} & =\phi\left[r_{t}^{\kappa}-r_{t}^{M}-\lambda_{t} \chi\right] \\
r_{t}^{\kappa} & =r^{R}+\mu_{t}^{p} \\
N^{p}+M_{t} & =\kappa_{t}+R_{t}^{e}+R_{t}^{d, p} \\
N^{u} & =M_{t}+R_{t}^{d, u}
\end{aligned}
$$

Inequality constraints

$$
\begin{aligned}
\chi M_{t} & \leq\left(1-\delta_{t}\right) B_{t}^{D, p} \\
R_{t}^{d, p} & \geq 0 \\
R_{t}^{d, u} & \geq 0
\end{aligned}
$$

complementary slackness conditions

$$
\begin{aligned}
\lambda_{t}\left(0-\chi M_{t}+\left(1-\delta_{t}\right) B_{t}^{D, p}\right) & =0 \\
\mu_{t}^{p}\left(0+R_{t}^{d, p}\right) & =0, \\
\mu_{t}^{u}\left(0+R_{t}^{d, u}\right) & =0, \\
\lambda_{t}, \mu_{t}^{p}, \mu_{t}^{u} & \geq 0,
\end{aligned}
$$

In case of default $\left(\delta_{t}=1\right)$, we have $q_{t}=0$ such that our collateral constraint imposes $M_{t}=R_{t}^{e}=0$ and $r_{t}^{M}$ is undefined. All resources of unproductive banks are deposited at the central bank, $R_{t}^{d, u}=N^{u}$. The solution to the partial equilibrium in 
the unknowns under default $\left\{L_{t}, W_{t}, r_{t}^{\kappa}, \kappa_{, t}, R_{t}^{d, p}, \mu_{t}^{p}\right\}$ is then derived from the system:

$$
\begin{aligned}
W_{t} & =L_{t}^{\omega-1} \\
\kappa_{t} & =\eta W_{t} L_{t} \\
L_{t} & =\left[\frac{1+\eta r_{t}^{\kappa}}{(1-\alpha) e^{A_{t}} K^{\alpha}}\right]^{\frac{1}{1-\alpha-\omega}} \\
r_{t}^{\kappa} & =r^{R}+\mu_{t}^{p} \\
N^{p} & =\kappa_{t}+R_{t}^{d, p}
\end{aligned}
$$

with the inequality constraint $R_{t}^{d, p} \geq 0$, and complementary slackness condition

$$
\begin{aligned}
\mu_{t}^{p}\left(0+R_{t}^{d, p}\right) & =0 \\
\mu_{t}^{p} & \geq 0
\end{aligned}
$$

\section{C.3 Collateral choice}

We use the remaining dynamic equilibrium conditions to pin down the optimal amount of aggregate collateral holding for the consecutive period. We pin down the optimal choice over collateral $B_{t+1}^{D}$ from the system of equations:

$$
\begin{aligned}
N^{p}+D_{t}^{p} & =X_{t}^{p}-\left(1-\delta_{t}\right) q_{t} B_{t+1}^{D, p} \\
N^{u}+D_{t}^{u} & =X_{t}^{u}-\left(1-\delta_{t}\right) q_{t} B_{t+1}^{D, u} \\
\left(1-\delta_{t}\right) q_{t} & =\beta^{b} E_{t}\left[\mathcal{W}_{B^{D}}\left(B_{t+1}, B_{t+1}^{D}, A_{t+1}\right)\right]+\mu_{t}^{D} \\
B_{t+1}^{D} & =B_{t+1}^{D, p}+B_{t+1}^{D, u} \\
B_{t+1}+B_{t+1}^{D}+B_{t+1}^{*} & =0
\end{aligned}
$$

subject to the constraints

$$
\begin{aligned}
B_{t+1}^{D, \tau} \geq 0, & \tau \in\{p, u\} \\
D_{t}^{\tau} \geq 0, & \tau \in\{p, u\}
\end{aligned}
$$

The envelope condition is derived from bank value functions (C.3)-(C.5) and (C.6, C.15) which yields

$$
\begin{aligned}
\mathcal{W}_{B^{D}}\left(B_{t+1}, B_{t+1}^{D}, A_{t+1}\right) & =\pi^{p}\left[1-\delta_{t+1}+\lambda_{t+1}\right]+\pi^{u}\left(1-\delta_{t+1}\right) \\
& =1-\delta_{t+1}+\pi^{p} \lambda_{t+1}
\end{aligned}
$$

Since both types of banks have equal probabilities over funding needs in the consecutive period, the inter-temporal optimality conditions are identical. We aggregate over banks budget constraints in order to obtain the system of equations that pin down the 
optimal collateral choice:

$$
\begin{aligned}
& N+D_{t}=X_{t}^{p}+X_{t}^{u}-\left(1-\delta_{t}\right) q_{t} B_{t+1}^{D} \\
& D_{t}=\left(1-\delta_{t}\right) B_{t}^{D}+\left(1+r_{t}^{\kappa}\right) \kappa_{t}+\left(1+r^{R}\right) R_{t}-\left(1-\delta_{t}\right) q_{t} B_{t+1}^{D}-N \\
& \left(1-\delta_{t}\right) q_{t}=\beta^{b} E_{t}\left[1-\delta_{t+1}+\pi^{p} \lambda_{t+1}\right]+\mu_{t}^{D} \\
& B_{t+1}^{D}+B_{t+1}^{*}+B_{t+1}=0 \\
& B_{t+1}^{D}, D_{t} \geq 0
\end{aligned}
$$

Note that $E_{t}\left[1-\delta_{t+1}\right]=1-\pi_{t}^{\delta}$. Further, denoting aggregate cashflows in the financial sector by $X_{t}=X_{t}^{p}+X_{t}^{u}$, and noting the fact that in absence of default we have $\delta_{t}=0$, the optimal period $t$ collateral choice in the unknowns $\left\{B_{t+1}^{D}, B_{t+1}^{*}, D_{t}, \mu_{t}^{D}, \mu^{B^{D}}\right\}$ is fully described by the system

$$
\begin{gathered}
N+D_{t}=X_{t}-q_{t} B_{t+1}^{D} \\
q_{t}=\beta^{b}\left(1-\pi_{t}^{\delta}+\pi^{p} E_{t}\left[\lambda_{t+1}\right]\right)+\mu_{t}^{D} \\
B_{t+1}+B_{t+1}^{D}+B_{t+1}^{*}=0
\end{gathered}
$$

with the associated complementary slackness conditions

$$
\begin{gathered}
\mu_{t}^{D}\left(0+D_{t}\right)=0 \\
\mu_{t}^{B^{D}}\left(0+B_{t}^{D}\right)=0 \\
\mu_{t}^{D}, \mu_{t}^{B^{D}} \geq 0
\end{gathered}
$$

Under default we have $\delta_{t}=0$, hence $q_{t}=0$. It follows that $B_{t+1}=B_{t+1}^{D}=B_{t+1}^{*}=0$.

\section{C.4 Resource constraint}

The agents' budget constraints are used to form the aggregate resource constraint in the model economy:

$$
\begin{aligned}
C_{t}= & W_{t} L_{t}+D_{t}+T_{t}+\Pi_{t}^{N F} \\
\Pi_{t}^{N F}= & Y_{t}-W_{t} L_{t}-\kappa_{t} r_{t}^{\kappa} \\
D_{t}= & D_{t}^{p}+D_{t}^{u} \\
= & \left(1-\delta_{t}\right) B_{t}^{D, p}+\left(1+r_{t}^{\kappa}\right) \kappa_{t}-\left(1+r_{t}^{M}\right) M_{t}+\left(1+r^{R}\right) R_{t}^{p}-\left(1-\delta_{t}\right) q_{t} B_{t+1}^{D, p}-N^{p} \\
& +\left(1-\delta_{t}\right) B_{t}^{D, u}+\left(1+r_{t}^{M}\right) M_{t}+\left(1+r^{R}\right) R_{t}^{u}-\left(1-\delta_{t}\right) q_{t} B_{t+1}^{D, u}-N^{u} \\
= & \left(1-\delta_{t}\right) B_{t}^{D}+\left(1+r_{t}^{\kappa}\right) \kappa_{t}+\left(1+r^{R}\right) R_{t}-\left(1-\delta_{t}\right) q_{t} B_{t+1}^{D}-N \\
\Pi_{t}^{c b}= & -R_{t} r^{R} \\
T_{t}= & \Pi_{t}^{c b}+B_{t}-q_{t} B_{t+1}
\end{aligned}
$$


Summing over all agents' budget constraints, period $t$ consumption is determined in

$$
\begin{aligned}
C_{t} & =Y_{t}+\left(\kappa_{t}+R_{t}-N\right)+\left(1-\delta_{t}\right)\left(B_{t}+B_{t}^{D}\right)-\left(1-\delta_{t}\right) q_{t}\left(B_{t+1}+B_{t+1}^{D}\right) \\
& =Y_{t}+\left(1-\delta_{t}\right)\left(B_{t}+B_{t}^{D}\right)-\left(1-\delta_{t}\right) q_{t}\left(B_{t+1}+B_{t+1}^{D}\right)
\end{aligned}
$$

\section{Computational strategy}

The following algorithm proposes value function iteration in the discrete state space (DSS) as a solution to this numerical problem in a two-loop algorithm. ${ }^{47}$

1. Initiate the system. Form discrete grids over the three state variables with productivity $A \in \mathbb{A}=G_{A}\left\{A_{1}, A_{2}, \ldots, A_{i}\right\}$ of size $i$, government bonds $G_{B} \in$ $\mathbb{B}=\left\{B_{1}, B_{2}, \ldots, B_{j}\right\}$ of size $j$, and bonds held domestically as collateral $G_{D} \in \mathbb{D}$ $=\left\{B_{1}^{D}, B_{2}^{D}, \ldots, B_{p}^{D}\right\}$ of size $p$ with $B \in \mathbb{B}=\left[B_{\text {min }}, B_{\text {max }}\right], B^{D} \in \mathbb{F}=\left[B_{\text {min }}^{D}, B_{\text {max }}^{D}\right]$. Form a matrix $\mathbf{S}$ that represents the discrete state space and contains $s=i * j * p$ elements along the rows that represent the current state, $j$ elements along the columns for choice over $B^{\prime}$, and $p$ elements along the pages for choice over $B^{D \prime}$, hence $\mathbf{S}=s \times j \times p$. Form a second matrix, $\mathbf{S}^{\delta}=s \times 1$, that describes the state under default when choices are $B^{\prime}=B^{D^{\prime}}=0$. Note that the state space matrices $\mathbf{S}, \mathbf{S}^{\delta}$ do not have full rank, as all combinations that violate the condition $|B|>$ $B^{D}$ from condition (9) need to be eliminated from the state space. Initialize the government's value functions $\mathcal{V}_{(0)}\left(B, B^{D}, A\right), V_{(0)}^{d}\left(B, B^{D}, A\right)$, and $V_{(0)}^{n d}\left(B, B^{D}, A\right)$ of size $s \times 1$, and the bank pricing schedule for government debt of size $s \times j$.

2. Calculate period $t$ default allocations for each element in $\mathbf{S}^{\delta}$ using the system of partial equilibrium equations under default. Note that default allocations can be computed outside the pricing-loop as they are based on the assumption $q_{t}=0$ if $\delta_{t}=1$.

3. Take $q_{(0)}\left(B^{\prime}, B^{D \prime}, A\right)=1 /\left(1+r^{f}\right)$ for all combinations of current and future states $\mathbf{S}$ as the initial guess for the pricing-loop.

(a) Calculate period $t$ static allocations under repayment conditional on the state matrix $\mathbf{S}$ and the bond price $q_{(0)}$ by using the system of partial equilibrium equations in the repayment regime.

(b) Collateral policy:

i. Use the transition matrix $\Omega$ on the exogenous state to form expectations about future liquidity value of government bonds, $E_{t}\left(\lambda_{t+1}\right)$.

ii. Back out the optimal collateral decision for each potential choice of total government debt $B^{\prime}$, given current state $s$, denoted by $B^{F * \prime} \mid B^{\prime}$ $=\mathcal{F}\left(B, B^{D}, A\right)$ of size $s \times j$. The optimal collateral policy follows the optimality condition $E_{t}\left(\tilde{q}_{t}-q_{t}\right)=0+\mu_{t}^{D}+\mu_{t}^{B D}$.

(c) Government's value functions:

\footnotetext{
${ }^{47}$ The quasi-code is presented in recursive notation in this appendix. Variables for the consecutive period are denoted by a prime.
} 
i. Compute the value of household utility under repayment for each element of $\mathbf{S}$. Use the optimal collateral policy of banks $\mathcal{F}$ to form the continuation value of the government.

ii. Take default decision to form the default set $\Gamma^{\delta}\left(B, B^{D}, A\right)=s \times$ 1. In case of repayment, pin down optimal level of public debt $B^{\prime *}$. Obtain updated value functions $\mathcal{V}_{(1)}\left(B, B^{D}, A\right), V_{(1)}^{d}\left(B, B^{D}, A\right)$, and $V_{(1)}^{\text {nd }}\left(B, B^{D}, A\right)$.

iii. Iterate on government value functions until convergence is achieved.

iv. Back out the optimal debt policy of the government, consisting of the default decision $\delta_{t} \in\{0,1\}$, and the optimal borrowing decision $B^{\prime}$ in case of repayment. The vector of optimal government debt policy is of size $s \times 1$.

4. Use the default set $\Gamma^{\delta}\left(B, B^{D}, A\right)$ and the transition matrix $\Omega$ to form default probabilities $\pi_{(1)}^{\delta}$. Update the bond price equation. Convergence is achieved if $\left|q_{(0)}-q_{(1)}\right|<\varepsilon$. Else, update the bond price schedule $q_{(0)}=q_{(1)}$ and go back to step $3 a)$.

\section{E Data}

- Output: Quarterly GDP at constant prices. Spain: 2000q1 - 2011q4. Belgium, France, Germany, Greece, Ireland, Italy, Netherlands, Portugal: 2010q1-11q4. Source: OECD Quarterly National Accounts.

- Private consumption, Spain: Nominal quarterly consumption, deflated by the GDP deflator, 2001q1-2011q4. Source: National Statistics Institute (INE), Spain.

- Credit, Spain: Outstanding loans to non-financial corporations, up to 1 year, deflated by GDP deflator, 2003q1-2011q4. Source: Bank of Spain.

- Interbank loans, Spain: Deposits from domestic monetary financial institutions, Jan-2000 to Dec-2011 as a share in total liabilities. Source: Bank of Spain, Monetary and Financial Statistics.

- Risk-free rate, Spain: EONIA swap index rate, 3 month (short-term), starting Jun-2005 to Dec-2011. German Bund yield, 5 year (long-term), Jan-2000 to Dec2011. Source: Datastream.

- Sovereign spread, Spain: Spanish benchmark bond yield, 5 year, over German Bund, 20001q1 - 2011q4. Source: Datastream.

- Credit rate, Spain: Bank lending rate to non-financial corporations, up to 1 year, Mar-2003 to Dec-2012. (also: Belgium, France, Germany, Greece, Italy, Ireland, Netherlands, Portugal). Source: ECB.

- Interbank rate: GC repo rate, 3 month, Germany, France, Italy, Spain; 31Mar-2011 to 07-Dec-2011; Germany starts on 25-May-2011. Source: Bloomberg.

- Government debt: Total and domestic government debt, Spain, 2004q1 to 2013q1. Source: Arslanalp \& Tsuda (2012). 
- Bank liquid reserves to bank assets ratio, Spain: Ratio of domestic currency holdings and deposits with the monetary authorities to claims on other governments, nonfinancial public entities, the private sector, and other banking institutions, 2000-2011. Source: World Bank, World Development Indicators. 